Canadian

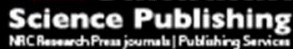

Canadian Geotechnical Journal Revue canadienne de géotechnique

\title{
Undrained monotonic and cyclic shear response and particle crushing of silica sand at low and high pressures
}

\begin{tabular}{|r|l|}
\hline Journal: & Canadian Geotechnical Journal \\
\hline Manuscript ID & cgj-2016-0212.R1 \\
\hline Manuscript Type: & Article \\
\hline Date Submitted by the Author: & 21 -Jul-2016 \\
\hline Complete List of Authors: & $\begin{array}{l}\text { Hyodo, Masayuki; Yamaguchi University } \\
\text { Wu, Yang; Yamaguchi university, Dept. of Civil and Environmental } \\
\text { Engineering } \\
\text { Aramaki, Noritaka; Northern Advancement Center for Science and } \\
\text { Technology, Horonobe Research Institute for the Subsurface Environment } \\
\text { Nakata, Yukio; Yamaguchi University, Civil \& Environmental Engineering }\end{array}$ \\
\hline Keyword: & $\begin{array}{l}\text { undrained shear behaviour, particle crushing, phase transformation state, } \\
\text { cyclic stress ratio, plastic work }\end{array}$ \\
\hline & \multicolumn{2}{|c}{} \\
\hline
\end{tabular}

\section{SCHOLARONE}

Manuscripts 


\title{
Undrained monotonic and cyclic shear response and particle crushing of silica sand at low and high pressures
}

\author{
Masayuki Hyodo, Professor \\ Department of Civil and Environmental Engineering \\ Yamaguchi University \\ Tokiwadai 2-16-1, Ube 755-8611, Japan \\ hyodo@yamaguchi-u.ac.jp \\ Yang $\mathrm{Wu}$ (Corresponding author), Postdoctral fellow \\ Department of Civil and Environmental Engineering \\ Yamaguchi University \\ Tokiwadai 2-16-1, Ube 755-8611, Japan \\ yangwuuu0226@hotmail.com \\ TEL: $+81-836-85-8363 \quad$ FAX: +81-836-85-9301 \\ Noritaka Aramaki, Chief researcher \\ Horonobe Research Institute for the Subsurface Environment, \\ Northern Advancement Center for Science and Technology \\ Sakaemachi 5-3, Horonobe-cho, Teshino-gun, Hokkaido 098-3221, Japan \\ noritaka.aramaki@h-rise.jp \\ Yukio Nakata, Professor \\ Department of Civil and Environmental Engineering \\ Yamaguchi University \\ Tokiwadai 2-16-1, Ube 755-8611, Japan \\ nakata@yamaguchi-u.ac.jp
}




\begin{abstract}
:
A series of undrained monotonic and cyclic triaxial tests were performed on silica sand at two initial densities and different confining pressures from $0.1 \mathrm{MPa}$ to $5 \mathrm{MPa}$ to investigate their shear response and crushing behaviour. The influence of particle crushing on the undrained shear strength and pore water pressure was examined. To clarify the evolution of particle crushing, undrained monotonic and cyclic tests were terminated at several distinctive stages and sieving analysis tests were subsequently performed on the tested specimens. In undrained monotonic test, specimens exhibited remarkable dilation behaviour and experienced no apparent particle crushing at low confining pressures. An increase in the mean stress suppressed the dilatancy due to a faster increase of the pore water pressure, giving rise to the occurrence of particle crushing. In undrained cyclic test, a higher confining pressure and cyclic stress ratio resulted in a much higher relative breakage. At a specific cyclic stress ratio, the relative breakage increased as the cyclic loading progressed. The confining pressure and shear strain amplitude played a significant role in controlling the evolution of particle breakage. The correlation between the relative breakage and plastic work for specimens under isotropic consolidation, undrained monotonic and cyclic loadings had been experimentally validated.
\end{abstract}

Key words: undrained shear behaviour, particle crushing, phase transformation state, cyclic stress ratio, plastic work. 


\section{Introduction}

Particle crushing of granular material has attracted many researchers in the past half century (Vesic and Clough 1968; Miura and O-Hara 1979; Miura et al. 1984; Hardin 1985; Hagerty et al. 1993; Lade et al. 1996; Nakata et al. 1999; Coop et al. 2004; Ovalle et al. 2014). Hard-grained sand is crushed in concentrated areas of significantly high mean and shear stresses, such as around the tip of a pile and at the bottom of a high dam (Yasufuku and Hyde 1995; Kuwajima et al. 2009; Wu et al. 2013; Wu and Yamamoto 2014). Particle crushing suppresses the dilatancy behaviour and increases the compressibility of granular material. Breakage of sand grain produces new smaller fine particles and alters the overall grading curve, furtherly affecting the mechanical and hydraulic characteristics. Accurate estimation of the particle crushing in engineering practice is beneficial for formulating a reasonable design plan and reducing the risk and loss from catastrophes.

Investigations on particle crushing in drained conditions have gained more attention than those in undrained cases. However, the liquefaction of weak-grained sand in port island areas was observed during the Hanshin earthquake in Kobe, Japan in 1995. In recent years, the methane hydrate existing at the bottom of seabed at high pressure and low temperature conditions has become a promising energy source. The static mechanical features of methane hydrate bearing sediment have been studied (Hyodo et al. 2005, 2013; Masui et al. 2005). However, the liquefaction strength of methane hydrate bearing sediment and hard-grained sand at high pressure remains unclear.

Despite the decrease in effective mean stress acting on the grains, some studies revealed the occurrence of particle crushing in undrained monotonic tests. Hyodo et al. (1996) confirmed the occurrence of breakage of Masado and Shirasu soil after undrained monotonic tests at low confining pressures. Several researchers (Lade and Yamamuro 1996; Bopp and Lade 2005; Shahnazari and Rezvani 2013) illustrated that the degree of particle crushing in undrained tests was lower compared to the drained tests because the 
effective mean stress sustained by soil particles was lower. Agustian and Goto (2008) observed substantial particle breakage of scoria specimens after undrained cyclic loading. The crushing behaviour of granular material subjected to cyclic loading in drained conditions has attracted the attentions of several researchers in recent decades (Donohue et al. 2009; López-Querol and Coop 2012; Sun et al. 2014).

In those studies, the influential parameters affecting the particle crushing of sand in undrained monotonic and cyclic tests were not well examined. Moreover, most of the particle breakage was observed for weak-grained sand in undrained tests at low confining pressures. In particular, the dynamic characteristic of hard-grained sand at high pressures is not fully understood, and the effect of particle breakage caused by cyclic loading is often neglected. Researchers (Hyodo et al. 2000, 2002; Orense et al. 2015) performed the undrained monotonic and cyclic undrained tests on dense sand and showed the degree of particle crushing at different stages during shearing. Although the surface area $S$ was employed to quantify the particle crushing, it was difficult to compare with other indexes, such as relative breakage $B_{r}$ (Hardin 1985; Einav 2007).

This study presents an experimental study on the undrained monotonic and cyclic shear response of silica sand at two initial densities at a wide range of confining pressures. The data for dense sand had been previously reported by (Hyodo et al. 2002). It is reanalyzed and data of medium-dense silica sand is supplemented to investigate the influence of initial density on the undrained shear and liquefaction strength, deformation, and crushing behaviour. This investigation intends to clarify the major parameters governing the crushing behaviour of Aio sand subjected to undrained monotonic and cyclic loadings and examine the evolution of particle crushing in the entire loading process and quantify the particle crushing using a reasonable index, relative breakage $B_{r}$ (Einav 2007). It facilitates the comparison of the results obtained with published data in the literature. The influence of particle crushing on the undrained shear strength and pore water pressure is examined and the different crushing mechanisms of medium-dense and dense sands 
are explained. Furthermore, the correlation between the relative breakage and plastic work per unit weight for specimens in undrained monotonic and cyclic tests are examined and its differences due to loading mode and initial density are interpreted.

\section{Material and experimental method}

Tested Aio sand (Yasufuku et al. 1994; Nakata et al. 1997a, 1997b) is a beach sand from the Yamaguchi prefecture in the south-west region of Honshu Island in Japan. Aio sand is characterized by the gradation shown in Fig. 1 and contains many sub-angular to angular hard grains. It is categorized as a silica sand and mainly consists of quartz and feldspar with rough surfaces, as shown in Fig. 2. The grain size distribution (GSD) curve of Aio sand varies from $2 \mathrm{~mm}$ down to $0.074 \mathrm{~mm}$. The specific gravity $G_{s}$ and uniform coefficient $U_{c}$ of Aio sand are 2.64 and 2.74, respectively, and the maximum and minimum void ratios are 0.958 and 0.582 , respectively.

Tests were conducted using a high-pressure triaxial testing apparatus. The high-pressure apparatus equipped with the hydraulic servo system provides a maximum cell pressure of $50 \mathrm{MPa}$ and a wide range of cyclic loading frequencies from $0.001 \mathrm{~Hz}$ to $100 \mathrm{~Hz}$. All specimens were formed by air pluviation methods to attain the target void ratios $e_{i}=0.760$ (medium-dense state with initial relative density of 50\%) and 0.657 (dense state with initial relative density of $80 \%$ ) and an initial density $\rho_{d}=1590 \mathrm{~kg} / \mathrm{cm}^{3}$. The cylindrical specimens had a diameter of $50 \mathrm{~mm}$ and a height of approximate $100 \mathrm{~mm}$. The specimens were isotropically consolidated to different effective mean stresses of $0.1 \mathrm{MPa}, 3 \mathrm{MPa}$, and $5 \mathrm{MPa}$. The axial strain, axial displacement, cell pressure, and excess pore water pressure were automatically recorded via a computer.

A series of undrained compression and extension monotonic tests were performed on specimens at 
confining pressures from low to high at a constant shear strain rate of $0.1 \% / \mathrm{min}$. To clarify the evolution of particle crushing of silica sand subjected to undrained monotonic loading, a series of undrained monotonic triaxial tests were performed and terminated at several distinctive stages. Further, at a specific density and confining pressure, another three tests, including one drained isotropic consolidation test and two undrained monotonic triaxial tests terminated at the phase transformation point and steady state point, were performed. The steady state (SS) (Castro and Poulos 1977; Poulos 1981) was regarded as synonymous to the critical state (CS) in many investigations (Castro and Poulos 1977; Poulos 1981) and this study conformed to this consensus.

The cyclic loading was axially conducted by uniform sinusoidal cycles on specimens under stress controlled at different cyclic stress ratios (CSR) $\sigma_{d} / 2 \sigma_{c}^{\prime}$ with a frequency of $0.05 \mathrm{~Hz}$. Herein, the imposed cyclic stress ratio was defined as the ratio of the deviatoric stress $\sigma_{d}$ to the confining pressure $\sigma_{c}^{\prime}$. The undrained cyclic tests were specially terminated after the first cycle, at the PT point, and at the failure state point under the same given experimental conditions of confining pressure $\sigma_{c}^{\prime}$, initial void ratio, and cyclic stress ratio $\sigma_{d} / 2 \sigma_{c}^{\prime}$. A sieving analysis was performed on the original specimens before testing and on tested specimens after different stages subjected to undrained monotonic and cyclic loadings.

\section{Isotropic consolidation tests and compression characteristics}

\section{Isotropic consolidation tests}

Figure 3 shows the void ratio plotted against the isotropic consolidation pressure for Aio sand at two initial void ratios under isotropic consolidation pressures from 0.02 $\mathrm{MPa}$ to $10 \mathrm{MPa}$. At the same density, the four curves, which terminated at different consolidation pressures, are shown. The yield stresses $p_{y}^{\prime}$ 
located at the point of the maximum curvature on the isotropic compression curve, which are marked with arrows in Fig. 3, for medium-dense and dense sands are around $2 \mathrm{MPa}$ and $3 \mathrm{MPa}$, respectively. Many researchers (Yasufuku et al. 1991; Hagerty et al. 1993; Nakata et al. 2001; Chuhan et al. 2003) noted that a major split in particle crushing commenced when the consolidation pressure exceeded the stress level at the yield point. Therefore, the confining pressures in undrained monotonic tests were selected as $0.1 \mathrm{MPa}, 3$ $\mathrm{MPa}, 5 \mathrm{MPa}$, which were below, approximately equal to, and beyond the yield stress $p_{y}^{\prime}$ on the isotropic compression curves for Aio sand. The compression index of Aio sand increases with a rise in the isotropic consolidation pressure regardless of the initial density. The two curves merge into one curve at an isotropic consolidation pressure around $9 \mathrm{MPa}$.

\section{Evaluation of particle crushing}

To quantify the amount of particle crushing, a series of parameters has been proposed to describe the variation in the GSD curves before and after grain breakage (Marsal 1967; Miura and Toyotoshi 1975; Lade et al. 1996). Hardin (1985) proposed a relative breakage index considering the variation in the overall GSD curve. This widely employed relative breakage $B_{r}$ is defined as an area ratio in Eq. (1).

$B_{r}=\frac{B_{t}}{B_{p}}$

Here, $B_{t}$ is the total breakage, and $B_{p}$ is the breakage potential. The relative breakage $B_{r}$ varies from zero to one.

The growth in understanding revealed that the actual ultimate GSD differed from the assumption of an 
arbitrarily specified cut-off value for diameter size. It has been widely recognized that the GSD tends to be fractal. Einav (2007) revised the relative breakage theory using continuum breakage mechanics and defined the ultimate cumulative distribution as $\left(d / d_{M}\right)^{3-\alpha}$, where $d$ is the grain diameter and $d_{M}$ is the maximum grain diameter. The fractal dimension $\alpha=2.6$ was adopted for natural sand (Coop et al. 2004). Figure 4 illustrates the definition of modified relative breakage $B_{r}$. The breakage potential $B_{p}$ is the area filled with the strip grid between the initial grading distribution curve $F_{o}(d)$ and the ultimate grading distribution curve $F_{u}(d)$. The total breakage $B_{t}$ is the gray area between the initial grading distribution curve $F_{o}(d)$ and the current grading distribution curve $F(d)$ after crushing. The ultimate grading distribution curve $F_{u}(d)$ is also shown in Fig. 1.

Figure 5 shows that the relative breakage $B_{r}$ increases with the increasing isotropic consolidation pressure. The relative breakage at the medium-dense state is larger than that at the dense state. It is believed that the specimen prepared at the dense state has a larger coordination number. Therefore, it results in a lower average contact stress acted on the particle and less particle crushing in the specimen at a higher density. Similar experimental results had also been reported by several researchers (Miura and Toyotoshi 1972; Yamamuro and Lade 1996; Shahnazari and Rezvani 2013).

\section{Undrained monotonic shear response and particle crushing}

\section{Stress-strain relationship}

Figures 6 (a) and 7 (a) show the stress-strain behaviour of Aio sand in undrained monotonic compression and extension triaxial tests with initial void ratios $e_{i}$ of 0.760 and 0.657 prior to isotropic consolidation. The corresponding effective stress paths of Aio sand are shown in Figs. 6 (b) and 7(b), respectively. The 
specimens show quite different responses at a wide range of confining pressures, which are below, approximately equivalent to, and beyond the yield stress $p_{y}^{\prime}$ determined from the isotropic compression curve. In the monotonic compression tests, the experimental results demonstrate that both medium-dense and dense specimens exhibit significant dilation behaviour at a low confining pressure $\sigma_{c}^{\prime}$ of $0.1 \mathrm{MPa}$ $\left(\sigma_{c}^{\prime}<p_{y}^{\prime}=2 \mathrm{MPa}\right.$ for the medium-dense state, $3 \mathrm{MPa}$ for the dense state). However, the dilation is largely suppressed as the confining pressure is increased to $3 \mathrm{MPa}$ and $5 \mathrm{MPa}\left(\sigma_{c}^{\prime}>p_{y}^{\prime}=2 \mathrm{MPa}\right.$ for the medium-dense state, $3 \mathrm{MPa}$ for the dense state). The specimen attains the PT points marked in Figs. 6 (a) and 7 (a) at a small axial strain level, and the axial strain rapidly increases with limited mobilised strength gains beyond the PT point. For Aio sand at confining pressures of $3 \mathrm{MPa}$ and $5 \mathrm{MPa}$, the effective stress path initially moves toward the right side (dilation side) and finally terminates in the net contraction side. The undrained shear behaviour of hard-grained sand at high pressures was noted to be similar to that of carbonate sand, a weak-grain sand, at low pressures (Coop 1990; Hyodo et al. 1998). However, the shape of crushable sands such as decomposed sand, calcareous sand and volcanic soil is quite angular. The initial shear behaviour of crushable soil is affected by its angular shape but this influence gradually becomes weak accompanied by particle breakage during shearing. The stress ratio at the PT point in the compression side is approximately equal to 1.42 and that in the extension side is -0.75 . This difference results from the loading mode and naturally anisotropic characteristics of Aio sand.

Figure 8 shows the state paths of specimens in undrained monotonic tests in the specific volume $v$ and logarithmic isotropic consolidation pressure space. A unique critical state line which fits well with the all test termination points can be drawn and expressed with the equation adopted by (Li and Wang 1998; Vilhar et al. 2013). The critical sate line is curved at low pressures and becomes straight at high pressures. The void ratio after isotropic consolidation $e_{c}$ and state parameter $\psi$ prior to shearing (Been and Jefferies (1985)) of each test are depicted in Fig. 8. The disappearance of strong dilation behaviour of specimens 
accompanied by a faster increase of the pore water pressure is noticed as the state parameter changes from negative state to positive state. Figure 9 presents that the normalized shear strength $q / 2 \sigma_{c}^{\prime}$ at CS point tends to decrease as the state parameter varies from negative state to positive state. The plots for both of medium-dense and dense Aio sands can be described using a unique expression.

\section{Evolution of particle crushing in undrained monotonic tests}

Figures 10 (a) and 10 (b) present the GSD curves of medium-dense specimens at different intermediate stages in undrained monotonic tests at confining pressures of $0.1 \mathrm{MPa}$ and $3 \mathrm{MPa}$. The experimental results indicate that there is a slight difference in the GSD curves at different stages at a low confining pressure of 0.1 MPa. A remarkable change in the grading curves for specimens at different stages was noticed at a confining pressure of $3 \mathrm{MPa}\left(\sigma_{c}^{\prime}>p_{y}^{\prime}=2.0 \mathrm{MPa}\right)$, as shown in Fig. $10(\mathrm{~b})$. It is clear that the major change in the GSD curves occurs between the PT point and the CS point. Owing to the effects of the "necking" phenomena in the extension side, the evolution of particle crushing is only discussed in the compression side. Figure 11 shows the relative breakage $B_{r}$ plotted against the confining pressure for both medium-dense and dense Aio sands. Less particle crushing occurs at a low confining pressure of $0.1 \mathrm{MPa}$. The relative breakages, determined after consolidation, at the PT point, and at the CS point, increase as the consolidation pressure increases. The amount of particle crushing significantly increases after the PT point and continues to increase until the CS point regardless of the initial density. The variant tendencies of the relative breakage with the confining pressures for both medium-dense and dense sands are quite similar. The relative breakages, determined after consolidation and at the PT point, are smaller for dense sand. At the CS point, the dense specimen sustained a higher deviatoric stress has a larger relative breakage.

Figure 12 shows the relative breakage plotted against the axial strain of Aio sand at the medium-dense 
and dense states. The experimental results demonstrate that the relative breakage exhibits an approximately linear relation with the axial strain at all confining pressures. Moreover, this increasing rate of relative breakage with the axial strain is remarkable at higher confining pressures. A small amount of particle breakage before the PT point is resulted from the specimen reaching the PT point at an earlier stage with a small axial strain. Moreover, the effective mean stress on the particles decreases during this stage. Beyond the PT point, the continually increasing deviatoric and axial strain cause a larger amount of particle crushing in undrained monotonic tests. The effective mean stress also reverses to increase until reaching the CS point, although it is still less than the initial consolidation pressure.

\section{Influence of particle crushing on undrained shear strength and pore water pressure}

The mechanical strength and deformation behaviour experience significant change before and after particle crushing in undrained monotonic tests. The pore water pressure $u_{d}$ is adopted to describe the dilatancy characteristics of sand. To eliminate the effect of the confining pressure, the normalized undrained mobilised strength $q / 2 \sigma_{c}^{\prime}$ and the normalized pore pressure ratio $u_{d} / \sigma_{c}^{\prime}$ are adopted and deliberately decided at the PT and CS points, respectively. Figure 13 shows the variations in the normalized mobilised undrained shear strength and normalized pore pressure ratio at the PT point and the CS point with the increasing confining pressures for the medium-dense and dense Aio sands. The undrained mobilised strength at the PT point $\left(q / 2 \sigma_{c}^{\prime}\right)_{\mathrm{PT}}$ of the medium-dense Aio sand initially increases, as the confining pressure varies from $0.1 \mathrm{MPa}$ to $3 \mathrm{MPa}$, and subsequently decreases at a confining pressure of 5 MPa. However, the normalized undrained shear strength of medium-dense Aio sand at the CS point $\left(q / 2 \sigma_{c}^{\prime}\right)_{\mathrm{CS}}$ consistently decreases as the confining pressure increases. For dense Aio sand, both the mobilised undrained shear strength $\left(q / 2 \sigma_{c}^{\prime}\right)_{\mathrm{PT}}$ at the PT point and $\left(q / 2 \sigma_{c}^{\prime}\right)_{\mathrm{CS}}$ at the CS point decrease 
with increasing confining pressure. In drained triaxial tests, researchers (Miura and O-Hara 1979; Yamamuro and Lade 1996; Russell and Khalili 2004; Indraratna et al. 2015) also reported that the peak shear strength decreased as the confining pressure was increased. The consequence of this tendency is the continual breakdown and rearrangement of the bearing particles in the specimens. The normalized pore pressure ratios $\left(u_{d} / \sigma_{c}^{\prime}\right)_{\mathrm{PT}}$ and $\left(u_{d} / \sigma_{c}^{\prime}\right)_{\mathrm{CS}}$ exhibit the opposite tendency to the normalized shear strength with changes in the confining pressures. The normalized pore pressure ratio $\left(u_{d} / \sigma_{c}^{\prime}\right)_{\mathrm{CS}}$ at the CS point varies from a negative value to a positive value. A positive pore water pressure indicates the contractive behaviour of sand accompanied by a decreasing undrained shear strength in undrained monotonic tests. In contrast, the dilative behaviour of sand usually corresponds to a high undrained shear strength.

\section{Undrained cyclic shear response and particle crushing}

\section{Stress-strain relationship}

Figures 14 (a) and 14 (b) show the undrained cyclic response of dense Aio sand. The dense specimens are isotropically consolidated to a confining pressure of $0.1 \mathrm{MPa}\left(\sigma_{c}^{\prime}<p_{y}^{\prime}=3 \mathrm{MPa}\right.$ for the dense state $)$ and cycled at a cyclic stress ratio $\sigma_{d} / 2 \sigma_{c}^{\prime}$ of 0.390 . The effective mean stress quickly reduces and the specimen becomes softer when accompanied by the generation of the excess pore water pressure $u$ as the cyclic loading proceeds. A larger axial strain, triggered by the rapid build-up of the excess pore water pressure $u$, eventually causes the dense specimens to decrease in strength. An axial strain amplitude is produced in the extension side in excess of 5\%. The effective mean stress of dense Aio sand at pressures decreases to zero. The cyclic mobility characterized by the progressive softening of a saturated sand specimen when subjected to cyclic loading at constant water content (Castro1969), is identified. The experimental results reveal that 
the stress ratio at the PT point subjected to monotonic loading is well consistent with that obtained in the cyclic loading in undrained conditions, as shown in Fig. 14 (b). Similar results have been reported in previous studies (Hyodo et al. 1998; Wijewickreme et al. 2010; Konstadinou and Georgiannou 2013; Salem et al. 2013).

Figures 15 (a) and 15 (b) present the stress-strain relationship and effective cyclic stress path of dense Aio sand at a confining pressure of $5 \mathrm{MPa}\left(\sigma_{c}^{\prime}>p_{y}^{\prime}=3 \mathrm{MPa}\right.$ for the dense state). Castro and Poulos (1977) illustared that sands lied above the critical state line showing the contractive behaviour and were subject to possible liqufaction under dynamic shear loads. However, the effective mean stress of dense Aio sand at high pressures does not reach zero at failure state even if the specimen experiences a larger number of cycles. A substantial rise in pore pressure and axial strain is caused by the increasing cycles. This cyclic failure criterion is defined as the condition when a double amplitude (DA) of axial strain $\varepsilon_{D A}=5 \%$ is reached. The excessive deformation originated from the progressive stiffness degradation owing to the generation of excess pore water pressure.

\section{Liquefaction resistance strength curve}

Figure 16 presents the liquefaction resistance strength plotted against the cycle number of medium-dense and dense Aio sands. The liquefaction resistance strength is defined as the ratio of the applied cyclic stress to the confining pressure, $\sigma_{d} / 2 \sigma_{c}^{\prime}$. The dense Aio sand has a higher liquefaction resistance strength. The cyclic resistance strength of medium-dense and dense Aio sands tend to decrease as the applied confining pressure $\sigma_{c}^{\prime}$ is increased. Similar results on other types of sand have been reported by (Castro and Poulos 1977; Hyodo et al. 1998; Salem et al. 2013). Particle crushing has been identified as the major contributor to this tendency. The experimental results show that the slope of the liquefaction resistance strength curve 
increases with increasing density and decreasing confining pressure.

\section{Effect of cyclic stress ratio on particle crushing}

Figures 17 and 18 show that the relative breakage $B_{r}$ plotted against the cyclic stress ratio of medium-dense and dense Aio sands, respectively. Particle crushing is also assessed in isotropic consolidation tests to differentiate the particle damage solely by cyclic loading. Thus, the relative breakage $B_{r}$ is a non-zero value at $\sigma_{d} / 2 \sigma_{c}^{\prime}=0$. At a low confining pressure $\sigma_{c}^{\prime}=0.1 \mathrm{MPa}\left(\sigma_{c}^{\prime}<p_{y}^{\prime}=2 \mathrm{MPa}\right.$ for the medium-dense state, $3 \mathrm{MPa}$ for the dense state), a minimal rise in the relative breakage $B_{r}$ is observed with increasing cyclic stress ratio $\sigma_{d} / 2 \sigma_{c}^{\prime}$, as shown in Figs. 17 and 18. The relative breakage of medium-dense and dense Aio sands indicates a markedly increasing tendency when the confining pressures $\sigma_{c}^{\prime}$ is

approximately equal to or greater than the yield stress $p_{y}^{\prime}\left(p_{y}^{\prime}=2 \mathrm{MPa}\right.$ for the medium-dense state, $p_{y}^{\prime}=$ $3 \mathrm{MPa}$ for the dense state). The experimental data is slightly scattered at a confining pressure of $5 \mathrm{MPa}$, as shown in Fig. 18. It is still noted that the relative breakage is slightly higher for dense specimens. The dense specimens require a higher cycle number to attain the liquefaction strength curve at the same cyclic stress ratio as shown in Fig. 16. Thus, additional plastic work is dissipated on the dense sand and it gives rise to the slightly higher particle breakage for dense specimens. It is interesting here to note that the particle crushing indeed occurs after a number of cyclic loadings in undrained conditions; although, the effective mean stress continually decreases. This is attributed to the high-level strain developed as the cyclic loading progresses.

Evolution of particle crushing in undrained cyclic tests 
To investigate the evolution of particle crushing in undrained cyclic loading at a given cyclic stress ratio, the tests were terminated at three distinctive stages, including after the first cycle, at the PT point, and at the failure state point when the double amplitude of axial strain $\varepsilon_{D A}=5 \%$ is reached. Figures 19 shows the designated stress paths of dense Aio sand at two cyclic stress ratios. The undrained cyclic test on dense Aio sand is also terminated at an additional stage after twenty cycles $(N=20)$ at a cyclic stress ratio $\sigma_{d} / 2 \sigma_{c}^{\prime}=$ 0.203 . Figures 20 shows the variation in the GSD curves of Aio sand at dense state $\left(\sigma_{c}^{\prime}=5 \mathrm{MPa}, \sigma_{d} / 2 \sigma_{c}^{\prime}=\right.$ 0.285) before testing and after several distinctive stages. A gradual shift of the grading curves is confirmed, accompanied by the stress paths proceeding from one cycle to the PT point and finally the failure state.

Figure 21 shows the evolution of the relative breakage $B_{r}$ of dense Aio sand with increasing cycle number $N$ at two cyclic stress ratios and a confining pressure $\sigma_{c}^{\prime}=5 \mathrm{MPa}$. The separate points from (b-1) to (c-4) in correspond to those in Fig. 19. Contour lines representing the PT state point and the failure state point are also drawn, intersecting with the curve expressing the evolution of the relative breakage. Moreover, the contour lines exhibit an opposite variable tendency to the relative breakage evolution curve with the level of cycle number $N$. A lower cycle number $N$ is required to reach the failure state at a higher cyclic stress ratio.

At a specific cyclic stress ratio, the relative breakage increases as the cycle number $N$ progresses. But, the cycle number corresponding to the failure state is greatly dependent on the cyclic stress ratio. No remarkable particle crushing occurs after the first cyclic loading but a slight difference in the relative breakage is observed after the first cycle at two different cyclic stress ratios. A larger amount of particle crushing occurs at a higher cyclic stress ratio of $\sigma_{d} / 2 \sigma_{c}^{\prime}=0.285$. Majority of particle crushing is produced and the stiffness of specimen degrades after the specimen passes through the PT point $\left(\sigma_{d} / 2 \sigma_{c}^{\prime}=0.285, N\right.$ $=3 ; \sigma_{d} / 2 \sigma_{c}^{\prime}=0.203, N=40$ ). This is resulted from the high-level axial strain induced by the particle rotation and translation. Orense et al. (2015) studied the crushing behaviour of pumice sand in a series of 
undrained cyclic tests and presented a similar variable tendency of particle crushing as for the number of cycles. It is inferred that the particle breakage evolution curve becomes flatter as the cyclic stress ratio decreases.

It is noted that the level of confining pressure is a crucial parameter in causing particle crushing in both undrained monotonic and cyclic tests. This is attributed to the decrease in dilative behaviour accompanied with the rapid rise in pore pressure when the mean stress increases. Within the range of undrained cyclic loading, the level of confining pressure and shear strain amplitude play a significant role in governing the development of particle crushing. A rise in the cyclic stress ratio (decrease in the required cycle number in accordance with the failure state) also increases the amount of particle crushing. The density minimally affects the degree of particle crushing. The influence of density is not consistent with the results from undrained monotonic loading. It is deduced that the effect of parameters on the evolution of particle crushing within the undrained cyclic test attenuates in a descending order of level of confining pressure, shear strain amplitude, cyclic stress ratio (corresponding cycle number) and density.

\section{Effect of loading mode on particle crushing}

Figure 22 shows the original and re-determined GSD curves of dense Aio sand after both undrained monotonic and cyclic tests to investigate the effect of loading mode on the particle crushing in undrained conditions. The experimental results reveal that a rise in the cyclic stress ratio results in a larger relative breakage at a confining pressure $\sigma_{c}^{\prime}$ in excess of the corresponding yield stress $p_{y}^{\prime}$. Therefore, the grading curves after cyclic loading subjected to the maximum cyclic stress ratio are selected at the same level of confining pressure $\left(\sigma_{c}^{\prime}=3 \mathrm{MPa}, \sigma_{d} / 2 \sigma_{c}^{\prime}=0.328 ; \sigma_{c}^{\prime}=5 \mathrm{MPa}, \sigma_{d} / 2 \sigma_{c}^{\prime}=0.290\right)$. Substantial particle crushing occurs under monotonic loading compared with cyclic loading in undrained conditions. Such 
tendencies become obvious as the confining pressure is increased. This is due to the fact that the deviatoric stress in monotonic tests continually increases, accompanied by shearing, and its maximum value is significantly higher than that in the cyclic tests.

A distinctive difference in the GSD curves measured at CS in monotonic tests and failure state in cyclic tests is seen in Fig. 22. In undrained monotonic tests at high pressures, it is inferred that the crushing mode of particles contains the splitting of the particles and the breaking of asperities. The splitting of particles is caused by the continually increasing deviatoric stress, whilst fragmentation of the original grain is liable to occur in the corner points where the damaged grain is interlocked with the neighboring grains. For specimens subjected to undrained cyclic loading, the majority of the crushing mode is speculated to be the breaking of asperities of the particle. The direction switch of the cyclic stress from cycle to cycle changes the contact network among the grains such that the particles sustaining the larger contact forces are also altered. In contrast to the particle breakage under monotonic loading, the developed high-level axial strain induced by particle rotation and translation is regarded as the dominant factor in giving rise to the occurrence of particle damage.

\section{Relationship between plastic work and relative breakage}

Miura and O-Hara (1979) reported that the increase of the surface area increment $\Delta S$ was closely correlated to the plastic work $W_{p}$. Lade et al. (1996) established a unique relationship between the particle breakage index $B_{10}$ and the total energy dissipation, based on a series of tests on Cambria sand. The total energy dissipation is approximately identical to the plastic work $W_{p}$ because the elastic work is minimal compared to the magnitude of the total energy dissipation. Daouadji et al. $(2001,2010)$ integrated the influence of particle breakage with the elasto-plastic theory by altering the location of critical state line 
according to the evolution of the grain size distribution computed using a function of plastic work $W_{p}$. Zhang et al. (2013) proposed a similar equation and confirmed a close relationship between relative breakage and plastic work independent of particle strength and confining pressure. The plastic work $W_{p}$ is regarded as a comprehensive and suitable parameter to correlate the relative breakage $B_{r}$ because it contains both the stress and strain components.

\section{Determination of plastic work}

The method to determine the plastic work per unit volume of a specimen $W_{p}$ in undrained monotonic tests is specified here. The total energy dissipation or work increment $d E$ is composed of an elastic (recoverable) component $d U_{e}$ and a plastic (irrecoverable) component $d W_{p}$ by (Roscoe et al. 1963). $d U_{e}$ and $d W_{p}$ can be expressed by the products of stress and strain increments as shown in Eq. (2).

$\left.d E=d U_{e}+d W_{p}=p^{\prime}\left(d \varepsilon_{v}^{e}+d \varepsilon_{v}^{p}\right)+q d \varepsilon_{d}^{e}+d \varepsilon_{d}^{p}\right)$

Here, $p^{\prime}=\left(\sigma_{1}^{\prime}+\sigma_{2}^{\prime}+\sigma_{3}^{\prime}\right) / 3$ is the effective mean stress, $q=\sigma_{1}^{\prime}-\sigma_{3}^{\prime}$ is the deviatoric stress, and $\sigma_{1}^{\prime}, \sigma_{2}^{\prime}$ and $\sigma_{3}^{\prime}$ are the effective principal stresses. $d \varepsilon_{v}=d \varepsilon_{v}^{e}+d \varepsilon_{v}^{p}$ and $d \varepsilon_{d}=d \varepsilon_{d}^{e}+d \varepsilon_{d}^{p}$ are the volumetric and deviatoric strain increments, respectively. The superscripts $e$ and $p$ indicate the elastic and plastic portions, respectively. It follows the assumption by Roscoe et al. (1963) that the $q d \varepsilon_{d}^{e}$ is zero during the calculation process. Particle crushing has been proven to be an irrecoverable change and solely associated with the plastic work per unit volume of a specimen $W_{p} . W_{p}$ is obtained by extracting the elastic part $U_{e}$ from the total work $E$.

$W_{p}=\int p^{\prime} d \varepsilon_{v}+\int q d \varepsilon_{d}-\int p^{\prime} d \varepsilon_{v}^{e}$ 
The requirement of constant volume $\left(d \varepsilon_{v}=d \varepsilon_{v}^{e}+d \varepsilon_{v}^{p}=0\right)$ in undrained monotonic tests should be satisfied. Thus, the plastic work per unit volume of a specimen $W_{p}$ in Eq. (3) can be rewritten as the Eq. (4).

$W_{p}=\int q d \varepsilon_{d}-\int p^{\prime} d \varepsilon_{v}^{e}$

The elastic volumetric strain rate can be calculated using the equation $d \varepsilon_{v}^{e}=\kappa d p^{\prime} / p^{\prime} /\left(1+e_{i}\right)$ and the swelling index $\kappa$ is decided as 0.0117 with reference to the test results (Yasufuku et al. 1991). Owing to the elastic volumetric strain rate, $d \varepsilon_{v}^{e}$ is much smaller compared to the total deviatoric strain $d \varepsilon_{d}$ in Eq. (6). Thus, the amount of plastic work is greatly dependent on the magnitudes of the deviatoric stress and strain. The same method for calculating $W_{p}$ was employed by Miura and O-Hara (1979).

The total energy dissipation per unit volume per loading cycle $E$ during undrained cyclic loading can be decided using a simple method as the area of the stress-strain hysteresis loop (Figueroa et al. 1995, Ueng et al. 2010). The plastic work per unit volume per loading cycle $W_{p}$ in undrained cyclic test is assumed to be identical to the total energy dissipation per unit volume per loading cycle $E$ in this study. Besides, the plastic work per unit volume $W_{p}$ in drained isotropic consolidation process is determined as the effective mean stress multiplied by the plastic volumetric strain $\varepsilon_{v}^{p}$.

\section{Correlation between plastic work and relative breakage}

Figure 23 presents the plot of relative breakage $B_{r}$ against the plastic work of Aio sand at two densities in drained consolidation, undrained monotonic and cyclic tests. It is seen that the dissipation of plastic work per unit volume of specimen $W_{p}$ in the process of isotopic consolidation is much smaller than that 
consumed during shearing. In undrained monotonic tests, the relative breakage $B_{r}$ can be approximately expressed by the plastic work per unit volume of specimen $W_{p}$ using an experienced equation (Lade et al. 1996; $\mathrm{Hu}$ et al. 2011) regardless of the test termination stage and confining pressure at each density. However, an increase in initial density reduces the slope of this experienced curve. It is due to that the axial strain level of medium-dense sand is larger than that of dense sand at the same level of plastic work. The occurrence of particle crushing in dense specimens which in turn leads to the increase in deviatoric stress and the corresponding plastic work. Nguyen and Einav (2009) pointed out that the total energy dissipated for particle breakage involved a portion for creation of surface and another portion for load redistribution of stored energy from surrounding particles. A rise in the density of a specimen increases both the coordination number of particles and the portion for load redistribution of stored energy in the plastic work when particle breakage occurs. A unique correlation curve can be drawn between the relative breakage $B_{r}$

and plastic work per unit volume of specimen $W_{p}$ for all specimens in undrained cyclic tests regardless of confining pressure and density. The slow increasing speed of relative breakage with plastic work increment is attributed to a relatively smaller amount of particle crushing in undrained cyclic tests. In comparison with the results from undrained monotonic tests, both the magnitudes of the relative breakage $B_{r}$ and plastic work $W_{p}$ are smaller as the deviatoric stress of specimens subjected to cyclic loading varies from the maximum deviatoric stress to the minimum deviatoric stress within a fixed range.

\section{Conclusion}

A series of undrained monotonic and cyclic triaxial tests were performed on Aio sand at two initial densities and a wide range of confining pressures. To examine the evolution of particle crushing, the tests were terminated at several distinctive stages. The sieving analysis tests were conducted on the original and 
tested specimens and the amount of particle crushing was quantified. The influence of particle crushing on the undrained shear strength and deformation characteristics was investigated. The relative breakage was experimentally verified to be a function of the plastic work for Aio sand in undrained conditions and the specific expression of the function was dependent upon the loading mode in undrained conditions and the initial density under undrained monotonic loading. The major findings of this study can be summarized as follow.

1. Both medium-dense and dense specimens exhibit significant dilation behaviour at a confining pressure of $0.1 \mathrm{MPa}$. The disappearance of strong dilation behaviour of specimens accompanied by a faster increase of the pore water pressure is noticed as the state parameter changes from negative state at confining pressure of $0.1 \mathrm{MPa}$ to positive state at confining pressures of $3 \mathrm{MPa}$ and $5 \mathrm{MPa}$. Negative pore water pressures at the CS point are observed for specimens at two densities at a confining pressure of $0.1 \mathrm{MPa}$. It increases to a positive value as the confining pressure increases from $0.1 \mathrm{MPa}$ to $5 \mathrm{MPa}$.

2. In undrained monotonic test, less particle crushing occurs at a low confining pressure of $0.1 \mathrm{MPa}$ and particle crushing becomes remarkable as the confining pressure exceeds the level of the yield stress on isotropic compression curve. Increasing mean stress suppresses the dilative behaviour accompanied by a rapid rise in pore water pressure, thus resulting in the occurrence of particle crushing and a remarkable contractive behaviour of the specimen. The relative breakage also increases with the increasing density. It is important to note that the majority of the particle crushing occurs between the PT point and the CS point of the specimen. The relative breakage approximately linearized with the axial strain at each confining pressure, and the rate of increase is dependent upon the confining pressure.

3. The difference in the particle breakage for medium-dense and dense sands results from the different 
crushing mechanism and the relatively larger deviatoric stress sustained by the dense specimen. The medium-dense specimen gradually becomes denser state owing to the filling of the voids among the particles with the grain fragments. The majority of the plastic work is consumed for dilatancy, and the undrained shear strength is gained. However, the plastic work for dense sand is mainly used for particle crushing with less used for dilatancy. This explains the decrease in the normalized undrained mobilised strength of dense sand at the PT point with certain confining pressures.

4. The confining pressure has a considerable effect on the liquefaction resistance strength of Aio sand. The cyclic resistance strength of Aio sand at two densities trends to decrease as the applied confining pressure $\sigma_{c}^{\prime}$ is increased. The liquefaction resistance strength reduction is mainly caused by particle crushing.

5. The relative breakage increases with the amplitude of the cyclic stress ratio $\sigma_{d} / 2 \sigma_{c}^{\prime}$, regardless of the density. At a given cyclic stress ratio $\sigma_{d} / 2 \sigma_{c}^{\prime}$, confining pressure, and density, the relative breakage increases as the cycle number $N$ progresses. Less particle crushing is observed after only one cyclic loading at two cyclic stress ratios. The majority of particle breakage is produced and the stiffness of specimen degrades after the specimen passes through the PT point. This is due to the high-level axial strain induced by the particle transformation and rotation. Similar to the undrained monotonic loading, the occurrence of particle crushing is attributed to the decrease in dilative behaviour accompanied with the rapid rise in pore pressure once the mean stress increases.

6. The particle crushing of Aio sand is greatly affected by the loading mode in undrained conditions. A distinctive difference in the GSD curves measured at CS in monotonic tests and failure state in cyclic tests is seen and this is due to different crushing modes of grains. In undrained monotonic tests, both of the deviatoric stress and axial strain continually increases as shearing stress persists. However, the deviatoric stress varies from the maximum deviatoric stress to the minimum deviatoric 
stress within a fixed range subjected to cyclic loading, and a large amount of particle crushing only commences when accompanied by the developed high-level axial strain. Additionally, the contact network among particles and the particles sustaining the larger contact forces changes from one cycle to the next, further reducing the possibility of particle breakage.

7. The correlation between the relative breakage and plastic work per unit volume for specimens under isotropic consolidation, undrained monotonic and cyclic loadings had been experimentally validated. It is demonstrated that a larger amount of plastic work is dissipated during the shearing process in comparison with that in isotropic consolidation. In undrained monotonic tests, the increasing rate of relative breakage with the plastic work decreases with a rise in the density. It is resulted from that a larger amount of plastic work is consumed for particle crushing and a higher deviatoric stress is obtained for dense sand. In undrained cyclic tests, the slope of the approximation curve between the relative breakage and plastic work per unit volume is less dependent on the density and lower than those determined in monotonic loadings as a consequence of a relatively smaller amount of particle breakage.

\section{Acknowledgement:}

A part of the work was supported by JSPS KAKENHI Grant-in-Aid Fundamental Research (A) of Grant No.25249065 and Grants-in-Aid for JSPS Fellows 15F15368. The authors wish to express their sincere thanks to the people concerned. 


\section{References:}

Agustian, Y., and Goto, S. 2008. Undrained Cyclic Shear Behaviour of Reconstituted Scoria Deposit. Soils and Foundations, 48(6): 851-857. doi: 10.3208/sandf.48.851.

Been, K., and Jefferies, M.G. 1985. A state parameter for sands. Géotechnique, 35(2): 99-112. doi:10.1680/geot.1985.35.2.99

Been, K., Jefferies, M.G. and Hachey, J. 1991. The critical state of sands. Géotechnique, 41(3): 365-381. doi:10.1680/geot.1991.41.3.365

Bopp, P.A., and Lade, P. V. 2005. Relative density effects on undrained sand behavior at high pressures. Soils and Foundations, 45(1): 15-26.

Castro, G. 1969. Liquefaction of Sand. Havard Soils Mechnics Series No.81, Harvard University.

Castro, G., and Poulos, S.J. 1977. Factors Affecting Liquefaction and Cyclic Mobility. Journal of the Geotechnical Engineering Division, 103(6): 501-506.

Chuhan, F.A., Kjeldstad, A., Bjørlykke, K., and Høeg, K. 2003. Experimental compression of loose sands: relevance to porosity reduction during burial in sedimentary basins. Canadian Geotechnical Journal, 40(5): 995-1011. doi: 10.1139/t03-050.

Coop, M.R. 1990. The mechanics of uncemented carbonate sands. Géotechnique, 40(4): 607-626. doi:10.1680/geot.1990.40.4.607

Coop, M.R., Sorensen, K.K., Freitas, T.B., and Georgoutsos, G. 2004. Particle breakage during shearing of a carbonate sand. Géotechnique, 54(3): 157-163. doi: 10.1680/geot.2004.54.3.157.

Daouadji, A., Hicher, P. Y., and Rahma, A. 2001. Elastoplastic model for granular materials taking into account grain breakage. European Journal of Mechanics, A/Solids, 20(1): 113-137. http://doi.org/10.1016/S0997-7538(00)01130-X

Daouadji, A., and Hicher, P.Y. 2010. An enhanced constitutive model for crushable granular materials. International Journal for Numerical and Analytical Methods in Geomechanics, 34(6): 555-580. doi:10.1002/nag.815

Donohue, S., O’Sullivan, C., and Long, M. 2009. Particle breakage during cyclic triaxial loading of a carbonate sand. Géotechnique, 59(5): 477-482. doi: 10.1680/geot.2008.T.003.

Einav, I. 2007. Breakage mechanics-Part I: Theory. Journal of the Mechanics and Physics of Solids, 55(6): 1274-1297. doi: 10.1016/j.jmps.2006.11.003.

Figueroa, J.L., and Liang, L. 1995. Evaluation of soil liquefaction by energy principles. Journal of Geotechnical $\quad$ Engineering, $\quad 120(9): \quad 1554-1569$. http://doi.org/10.1061/(ASCE)0733-9410(1994)120:9(1554) 
Hagerty, M.M., Hite, D.R., Ullrich, C.R., and Hagerty, D.J. 1993. One-Dimensional High-Pressure Compression of Granular Media. Journal of Geotechnical Engineering, 119(1): 1-18. doi:10.1061/(ASCE)0733-9410(1993)119:1(1).

Hardin, B.O. 1985. Crushing of soil particles. Journal of Geotechnical Engineering, 111(10): 1177-1192. doi: 10.1061/(ASCE)0733-9410(1985)111:10(1177).

Hu, W., Yin, Z., Dano, C., and Hicher, P.Y. 2011. A constitutive model for granular materials considering grain breakage. Science China Technological Sciences, 54(8): 2188-2196. doi:10.1007/s11431-011-4491-0

Hyodo, M., Aramaki, N., Takumi, O., Nakata, Y., and Hidekazu, M. 1996. Steady state and liquefaction strengths of crushable soils. Proceedings of Japanese Society of Civil Engineers, 554(III-37): 197209. doi: 10.2208/jscej.1996.554_197. (In Japanese)

Hyodo, M., Hyde, A.F.L., and Aramaki, N. 1998. Liquefaction of crushable soils. Géotechnique, 48(4): 527-543. doi: 10.1680/geot.1998.48.4.527.

Hyodo, M., Nakata, Y., Aramaki, N., Hyde, A.F.L., and Inoue, S. 2000. Liquefaction and particle crushing of soil. In Proceeding of 12th World Conf. on Earthquake Engineering. Auckland, 30 January Friday 4, New Zealand. pp. 0278 (1-8).

Hyodo, M., Hyde, A.F.L., Aramaki, N., and Nakata, Y. 2002. Undrained Monotonic and Cyclic Shear Behaviour of Sand under Low and High Confining Stresses. Soils and Foundations, 42(3): 63-76. doi: $10.3208 /$ sandf.42.3_63.

Hyodo, M., Nakata, Y., Yoshimoto, N., and Ebinuma, T. 2005. Basic Research on the Mechanical Behavior of Methane Hydrate-Sediments Mixture. Soils and Foundations, 45(1): 75-85.

Hyodo, M., Yoneda, J., Yoshimoto, N., and Nakata, Y. 2013. Mechanical and dissociation properties of methane hydrate-bearing sand in deep seabed. Soils and Foundations, 53(2): 299-314. doi: 10.1016/j.sandf.2013.02.010.

Indraratna, B., Sun, Q.D., and Nimbalkar, S. 2015. Observed and predicted behaviour of rail ballast under monotonic loading capturing particle breakage. Canadian Geotechnical Journal, 52(1): 73-86. doi: 10.1139/cgj-2013-0361.

Konstadinou, M., and Georgiannou, V.N. 2013. Cyclic Behaviour of Loose Anisotropically Consolidated Ottawa Sand under Undrained Torsional Loading. Geotechnique, 63(13): 1144-1158. doi: 10.1680/geot.13.P.090.

Kuwajima, K., Hyodo, M., and Hyde, A.F. 2009. Pile Bearing Capacity Factors and Soil Crushabiity. Journal of Geotechnical and Geoenvironmental Engineering, 135(7): 901-913. doi: 10.1061/(ASCE)GT.1943-5606.0000057. 
Lade, P. V., and Yamamuro, J.A. 1996. Undrained Sand Behavior in Axisymmetric Tests at High Pressures. Journal of Geotechnical Engineering, 122(2): 120-129. doi: 10.1061/(ASCE)0733-9410(1996)122:2(120).

Lade, P. V., Yamamuro, J.A., and Bopp, P.A. 1996. Significance of Particle Crushing in Granular Materials. Journal of Geotechnical and Geoenvironmental Engineering, 122(4): 309-316. doi:10.1061/(ASCE)1090-0241(1997)123:9(889).

Li, X.S., and Wang, Y. 1998. Linear Representation of Steady-State Line for Sand. Journal of Geotechnical $\begin{array}{llll}\text { and } & \text { Geoenvironmental } & \text { 124(12): }\end{array}$ doi:10.1061/(ASCE)1090-0241(1998)124:12(1215).

López-Querol, S., and Coop, M.R. 2012. Drained cyclic behaviour of loose Dogs Bay sand. Géotechnique, 62(4): 281-289. doi: 10.1680/geot.8.P.105.

Marsal, R.J. 1967. Large-Scale Testing of Rockfill Materials. Journal of the Soil Mechanics and Foundations Division, 93(2): 27-43.

Masui, A., Haneda, H., Ogata, Y., and Aoki, K. 2005. Effects of Methane Hydrate Formation on Shear Strength of Synthetic Methane Hydrate Sediments. In Proceeding of 5th International Conference on Gas Hydrates (ICGH 2005). Trondheim, 13-16 June 2005, Norway, pp. 364-369.

Miura, N., and Toyotoshi, Y. 1972. Compressibility of Sand Under High Isotropic Pressures. Proceedings of Japanese Society of Civil Engineers, 203: 45-52. doi: 10.2208/jscej1969.1972.45. (In Japanese)

Miura, N., and Toyotoshi, Y. 1975. Effect of Water on the Behavior of a Quartz-Rich Sand under High Stresses. Soils and Foundations, 15(4): 23-34. doi: 10.1248/cpb.37.3229.

Miura, N., and O-Hara, S. 1979. Particle-Crushing of a Decomposed Granite Soil under Shear Stresses. Soils and Foundations, 19(3): 1-14. doi: 10.3208/sandf1972.19.3_1.

Miura, N., Murata, H., and Yasufuku, N. 1984. Stress-strain characteristics of sand in a particle-crushing region. Soils and Foundations, 24(1): 77-89. doi: 10.3208/sandf1972.24.77.

Nakata, Y., Hyodo, M., Murata, H., Itakura, S., and Yamada, Y. 1997a. Effect of principal stress dictions on drained shear beahviour of carbonate sand. Memories of the Faculty of Engineering Yamaguchi University, 48(1): 57-64. (In Japanese)

Nakata, Y., Hyodo, M., Murata, Hidekazu, Kodama, S., and Adachi, T. 1997b. Strength anisotropy and particle crushing of sand under a wide stress region. Memories of the Faculty of Engineering Yamaguchi University, 48(1): 65-72. (In Japanese)

Nakata, Y., Hyde, A.F.L., Hyodo, M., and Murata, H. 1999. A probabilistic approach to sand particle crushing in the triaxial test. Géotechnique, 49(5): 567-583. doi: 10.1680/geot.1999.49.5.567. 
Nakata, Y., Hyodo, M., Hyde, A.F.L., Kato, Y., and Murata, H. 2001. Microscopic Particle Crushing of Sand Subjected to High Pressure One-Dimensional Compression. Soils and Foundations, 41(1): 6982. doi: 10.1139/cgj-2014-0079.

Nguyen, G. D., and Einav, I. 2009. The energetics of cataclasis based on breakage mechanics.Mechanics, Structure and Evolution of Fault Zones. Birkhäuser Basel, 1693-1724. doi: 10.1007/978-3-0346-0138-2_8.

Orense, R.P., Pender, M.J., and Liu, L. 2015. Effect of particle crushing on the dynamic properties of pumice sand. In Geomechanics from Micro to Macro. Edited by Kenichi Soga, Krishna kumar, Giovanna Biscontin and Matthew Kuo, CRC Press, London,UK, pp.1081-1086. doi: 10.1201/b17395-194.

Ovalle, C., Dano, C., Hicher, P. Y., and Cisternas, M. 2014. Experimental framework for evaluating the mechanical behavior of dry and wet crushable granular materials based on the particle breakage ratio. Canadian Geotechnical Journal, 52(5): 587-598. doi: 10.1139/cgj-2014-0079.

Roscoe, K.H., Schofield, A.N., and Thurairajah, A. 1963. Yielding of Clays in States Wetter than Critical. Géotechnique, 13(3): 211-240. doi: 10.1680/geot.1963.13.3.211.

Poulos, S.J., 1981. The Steady State of Deformation. Journal of the Geotechnical Engineering Division, 107(5): 553-562.

Russell, A.R., and Khalili, N. 2004. A bounding surface plasticity model for sands exhibiting particle crushing. Canadian Geotechnical Journal, 41(6): 1179-1192. doi: 10.1139/t04-065.

Salem, M., Elmamlouk, H., and Agaiby, S. 2013. Static and cyclic behavior of North Coast calcareous sand in Egypt. Soil Dynamics and Earthquake Engineering, 55: 83-91. doi: 10.1016/j.soildyn.2013.09.001.

Shahnazari, H., and Rezvani, R. 2013. Effective parameters for the particle breakage of calcareous sands: An experimental study. Engineering Geology, 159: 98-105. doi: 10.1016/j.enggeo.2013.03.005.

Sun, Q.D., Indraratna, B., and Nimbalkar, S. 2014. Effect of cyclic loading frequency on the permanent deformation and degradation of railway ballast. Géotechnique, 64(9): 746-751. doi: 10.1680/geot.14.T.015.

Ueng, T. S., Wu, M.C., Lin, C.Y., and Yu, R.Y. 2000. Pore Water Pressure Changes in Sands Under Earthquake. In Proceeding of 12th World Conf. on Earthquake Engineering. Auckland, 30 January Friday 4, New Zealand. pp. 1258 (1-7).

Verduguo, R., and Ishihara, K. 1996. The steady state of sandy soils. Soils and Foundations, 36(2): 81-91. doi:10.3208/sandf.36.2_81

Vesic, A.S., and Clough, G.W. 1968. Behavior of Granular Materials Under High Stresses. Journal of the Soil Mechanics and Foundations Division, 94(3): 661-688. 
Vilhar, G., Jovičić, V. and Coop, M.R. 2013. The role of particle breakage in the mechanics of a non-plastic silty sand. Soils and Foundations, 53(1): 91-104. doi:10.1016/j.sandf.2012.12.006

Wijewickreme, D., Khalili, A., and Wilson, G.W. 2010. Mechanical response of highly gap-graded mixtures of waste rock and tailings. Part II: Undrained cyclic and post-cyclic shear response. Canadian Geotechnical Journal, 47(5): 566-582. doi: 10.1139/T09-122.

Wu, Y., Yamamoto, H., and Yao, Y. 2013. Numerical study on bearing behavior of pile considering sand particle crushing. Geomechanics and Engineering, 5(3): 241-261. doi: 10.12989/gae.2013.5.3.241.

Wu, Y., and Yamamoto, H. 2014. Numerical Analysis of the Effect of Pile Tip Shape on Soil Behavior around Pile. Geotechnical Engineering Journal of the SEAGS \& AGSSEA, 45(2): 78-89.

Yamamuro, J.A., and Lade, P. V. 1996. Drained Sand Behavior in Axisymmetric Tests at High Pressures. Journal of Geotechnical Engineering, 122(2): 109-119. doi: 10.1061/(ASCE)0733-9410(1996)122:2(120).

Yamamuro, J.A., and Lade, P. V. 1998. Steady-State Concepts and Static Liquefaction of Silty Sands. Journal of Geotechnical and Geoenvironmental Engineering, 124(9): 868-877. doi:10.1061/(ASCE)1090-0241(1998)124:9(868)

Yasufuku, N., Murata, H., and Hyodo, M. 1991. Yield Characteristics of Anisotropically Consolidated Sand under Low and High Stresses. Soils and Foundations, 31(1): 95-109. doi: 10.3208/sandf1972.31.95.

Yasufuku, N., Tanaka, K., Murata, H., and Hyodo, M. 1994. End bearing capacity of pile in highly compressible sands and its evalution. Proceeding of Japanese Society of Civil Engineers, 505(III-37-29): 191-200. doi: 10.2208/jscej.1994.505_191. (In Japanese)

Yasufuku, N., and Hyde, A.F. 1995. Pile end-bearing capacity in crushable sands. Géotechnique, 45(4): 663-676. doi: 10.1680/geot.1995.45.4.663.

Zhang, B.Y., Jie, Y.X., and Kong, D.Z. 2013. Particle size distribution and relative breakage for a cement ellipsoid aggregate. Computers and Geotechnics, 53: 31-39. doi: 10.1016/j.compgeo.2013.04.007. 


\section{List of Figures Captions:}

Fig. 1 The original and ultimate grain size distribution curves of Aio sand

Fig. 2 Optical microscope image of Aio sand

Fig. 3 Isotropic compression curves of Aio sand with two initial void ratios of 0.760 and 0.657

Fig. 4 Definition of breakage index Br by Einav (2007)

Fig. 5 The relative breakage plotted against the isotropic consolidation pressure for Aio sand with two initial void ratios of 0.760 and 0.657

Fig. 6 Undrained monotonic shear behaviour of medium-dense Aio sand with initial void ratio 0.760 at variable confining pressures (a) Stress-strain behaviour (b) Effective stress path

Fig. 7 Undrained monotonic shear behaviour of dense Aio sand with initial void ratio 0.657 at variable confining pressures (a) Stress-strain behaviour (b) Effective stress path (Hyodo et al. (2002))

Fig. 8 State paths and end of test states on the specific volume and stress plane

Fig. 9 Normalized undrained shear strength at critical state and state parameter

Fig. 10 Grain size distribution curves of medium-dense Aio sand before testing, after consolidation, at phase transformation point and critical state point (a) At confining pressure of $0.1 \mathrm{MPa}$ (b) At confining pressure of 3.0 MPa

Fig. 11 Relative breakage after consolidation, phase transformation point and critical state point at variable confining pressures in undrained monotonic triaxial test

Fig. 12 The relative breakage plotted against the axial strain at variable confining pressures

Fig. 13 Normalized undrained shear strength and normalized pore pressure ratio plotted against confining pressure

Fig. 14 Undrained cyclic response of dense Aio sand at confining pressure of $0.1 \mathrm{MPa}$ (a) Stress-strain curve (b) Effective cyclic stress path (Hyodo et al. (2002)) 
Fig. 15 Undrained cyclic response of dense Aio sand at confining pressure of 5.0 MPa (a) Stress-strain curve (b) Effective cyclic stress path

Fig. 16 Liquefaction resistance strength of Aio sand with two initial void ratios of 0.760 and 0.657

Fig. 17 Relative breakage plotted against the cyclic stress ratio of medium-dense Aio sand

Fig. 18 Relative breakage plotted against the cyclic stress ratio of dense Aio sand

Fig. 19 Stress path at different cyclic stress ratios of dense Aio sand in undrained cyclic test (Hyodo et al. (2002))

Fig. 20 GSD curves of dense Aio sand at different stages in undrained cyclic test at confining pressure of $5.0 \mathrm{MPa}$

Fig. 21 The evolution of particle crushing at different cyclic stress ratios of dense Aio sand at confining pressure of 5.0 MPa in undrained cyclic test

Fig. 22 Effect of loading mode on the particle crushing in undrained conditions

Fig. 23 Correlation between relative breakage and plastic work under isotropic consolidation, undrained monotonic and cyclic tests 


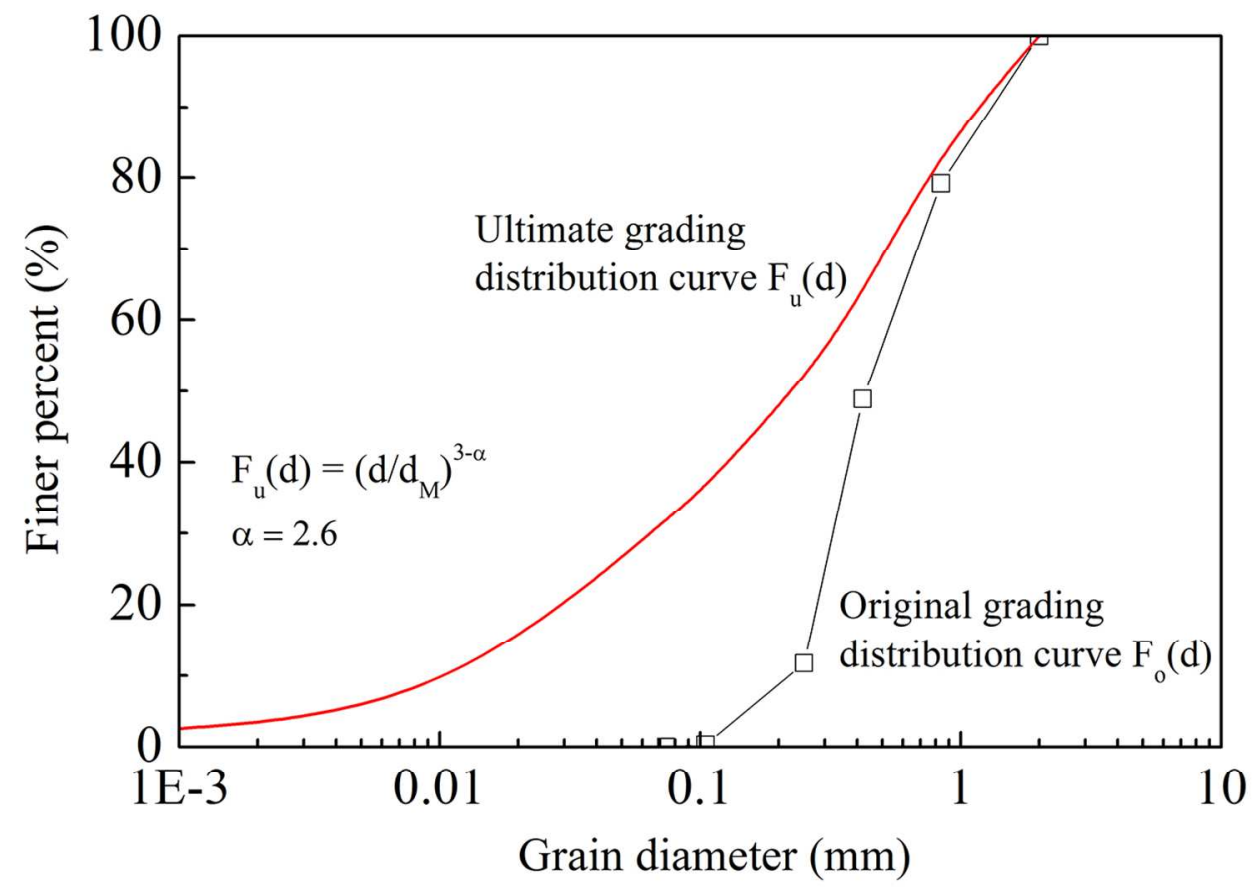

Fig. 1 The original and ultimate grain size distribution curves of Aio sand $119 \times 83 \mathrm{~mm}(300 \times 300 \mathrm{DPI})$ 


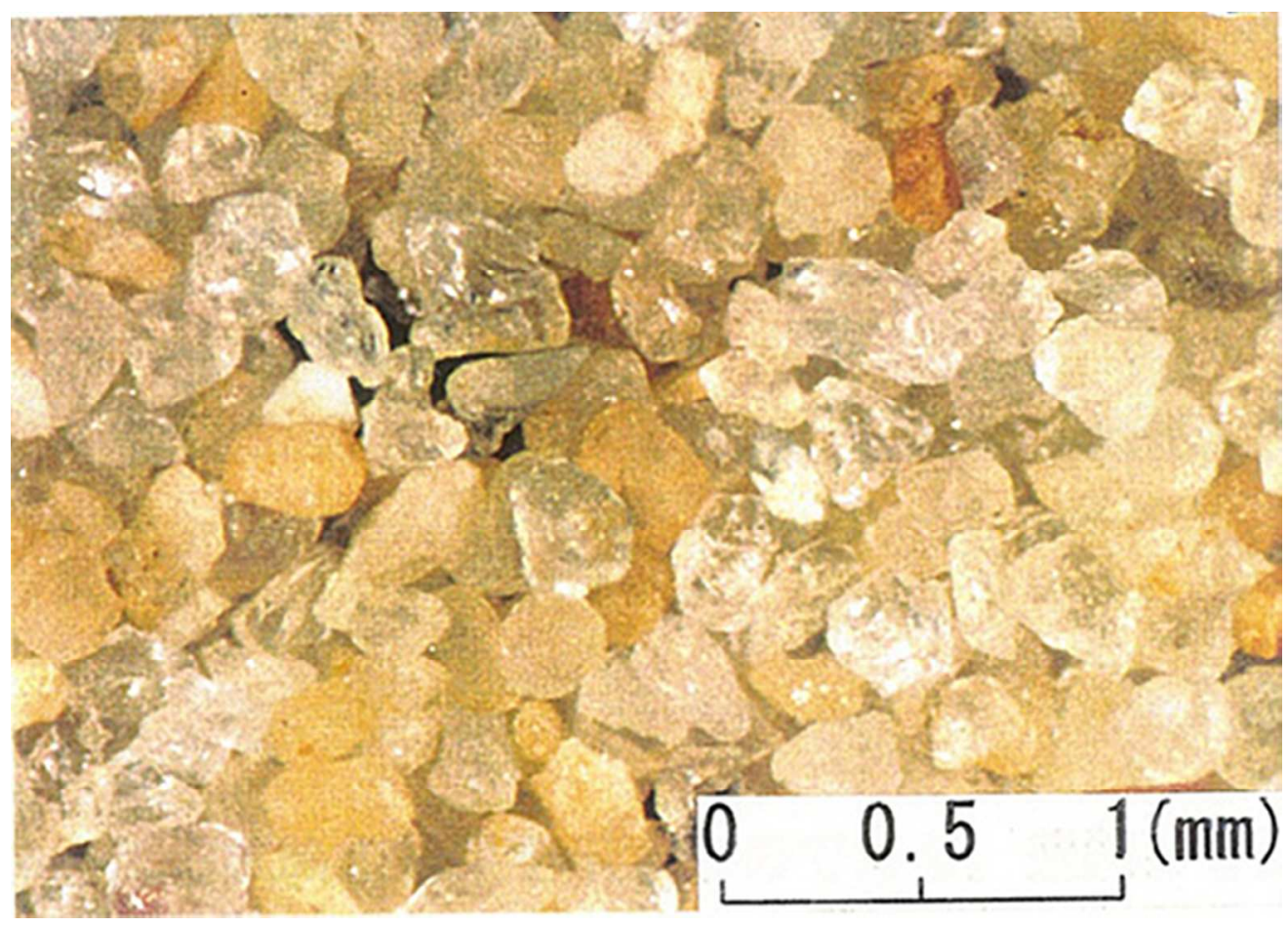

Fig. 2 Optical microscope image of Aio sand $60 \times 42 \mathrm{~mm}(300 \times 300$ DPI $)$ 


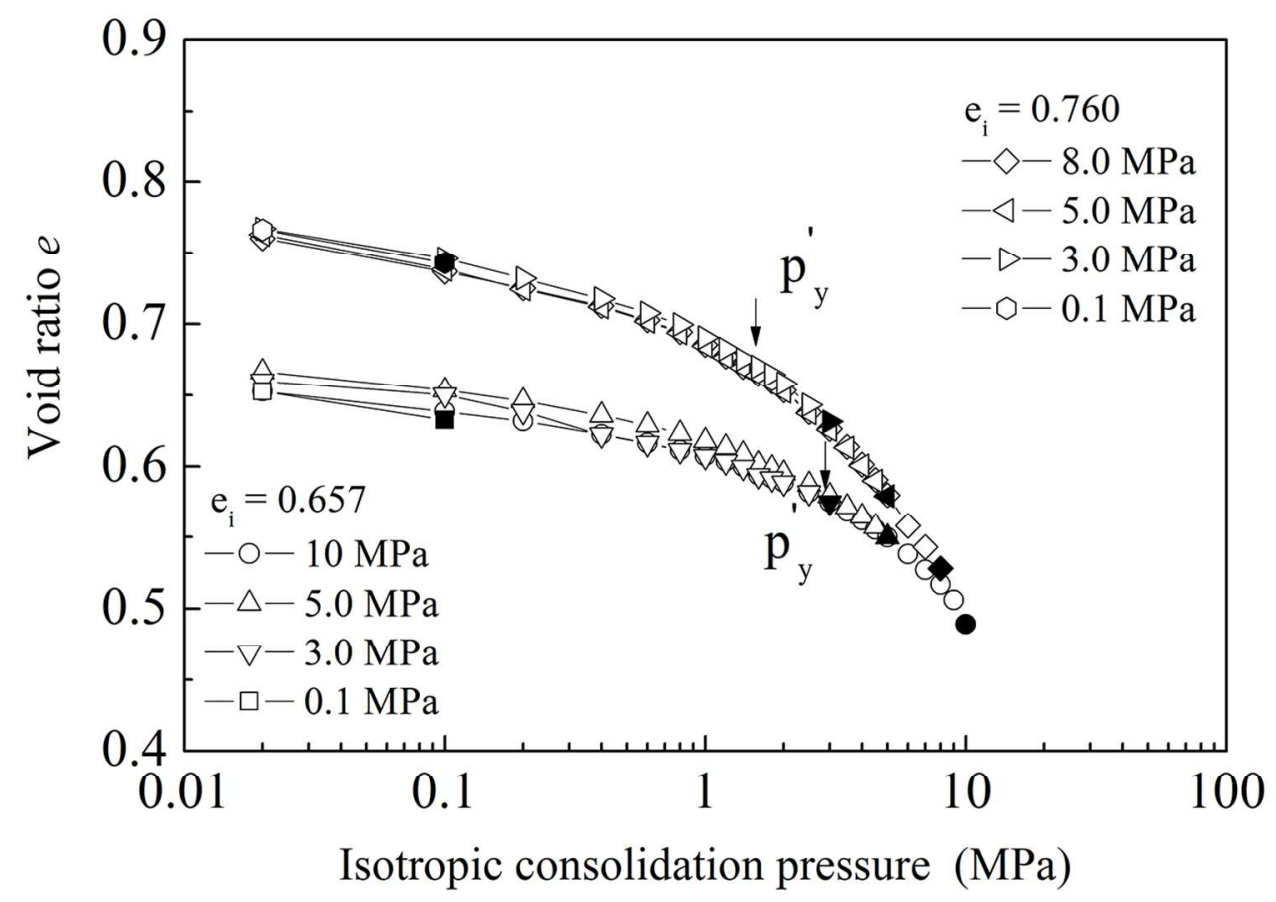

Fig. 3 Isotropic compression curves of Aio sand with two initial void ratios of 0.760 and 0.657 $119 \times 83 \mathrm{~mm}(300 \times 300 \mathrm{DPI})$ 


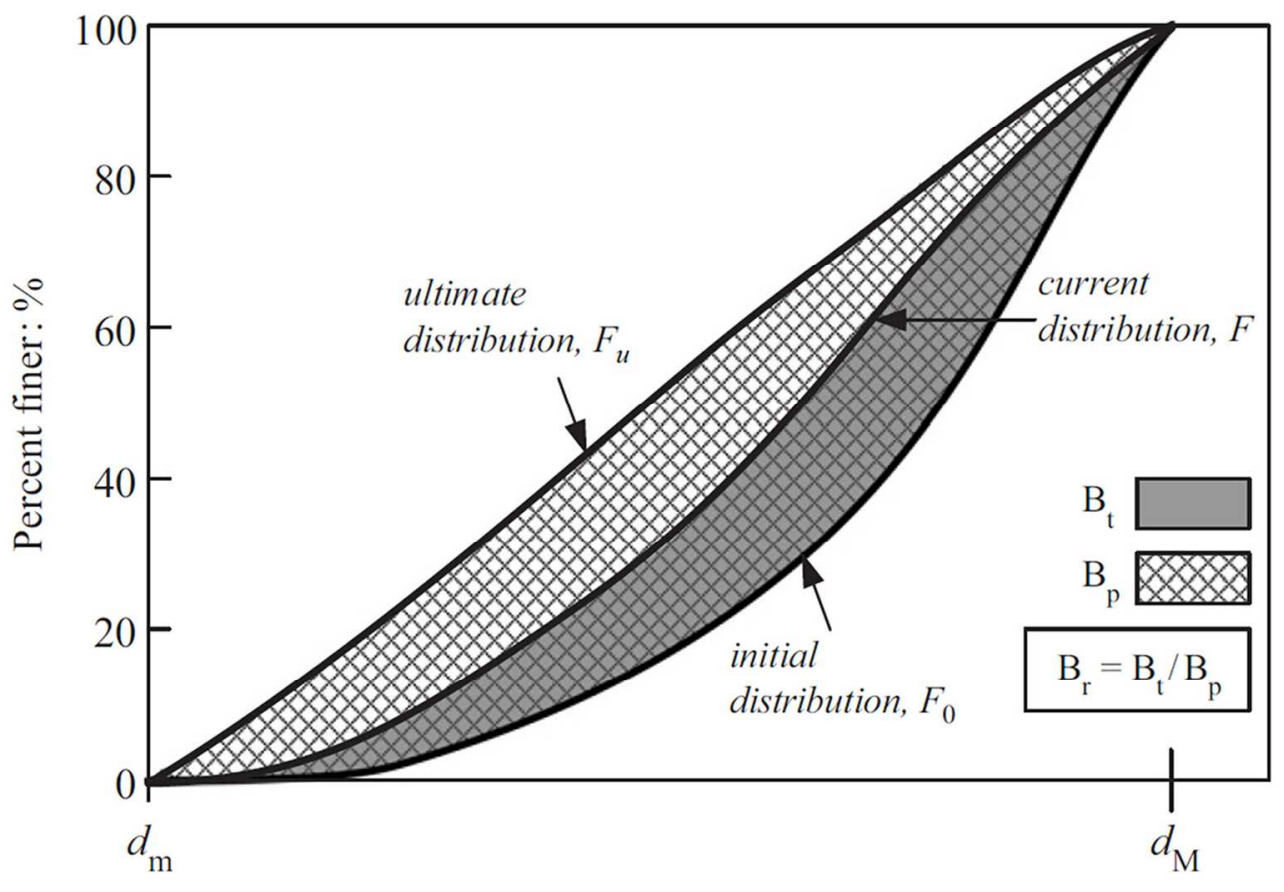

Grain size, $d$ (log scale)

Fig. 4 Definition of breakage index $\mathrm{Br}$ by Einav (2007)

$119 \times 89 \mathrm{~mm}(300 \times 300 \mathrm{DPI})$ 


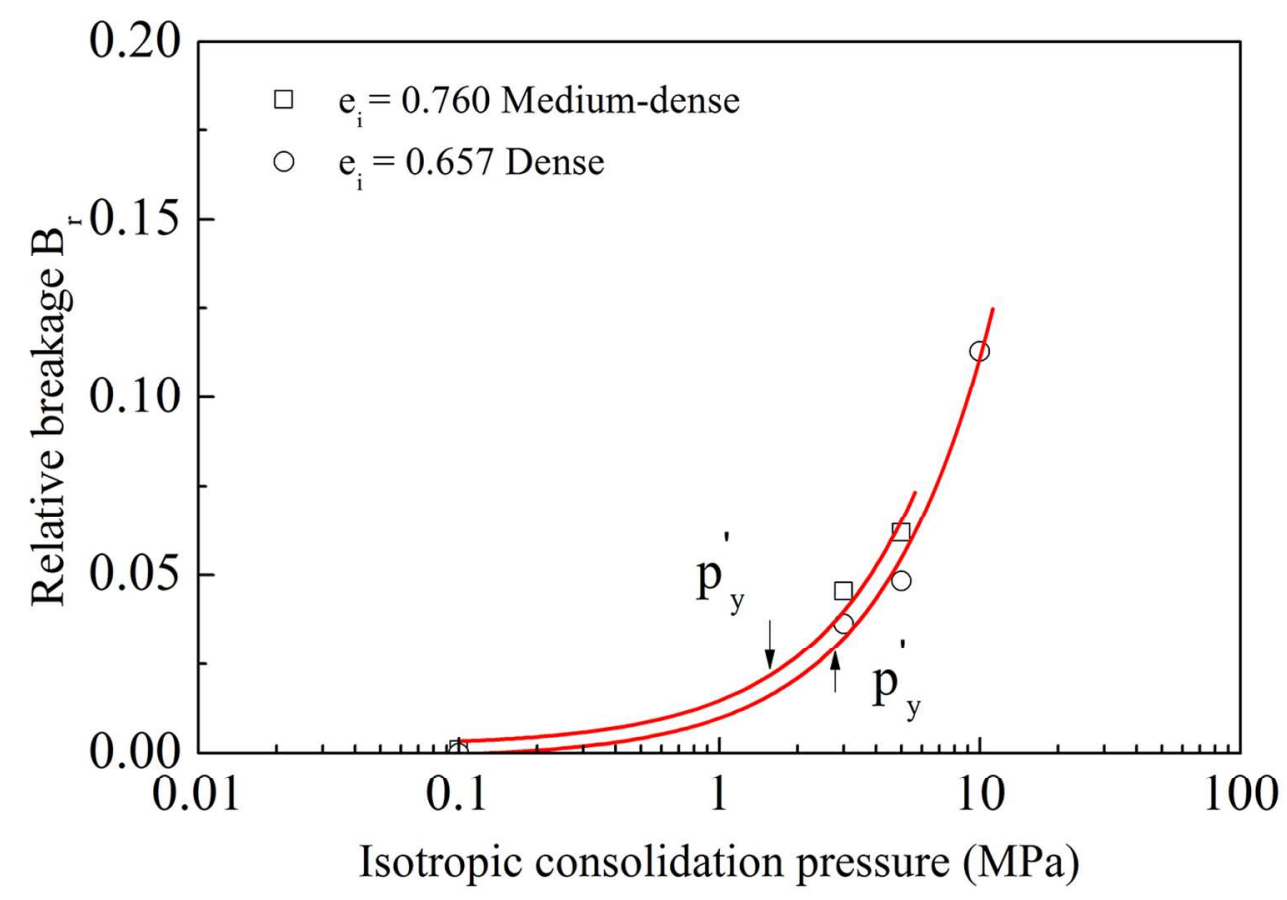

Fig. 5 The relative breakage plotted against the isotropic consolidation pressure for Aio sand with two initial void ratios of 0.760 and 0.657

$119 \times 83 \mathrm{~mm}(300 \times 300$ DPI $)$ 

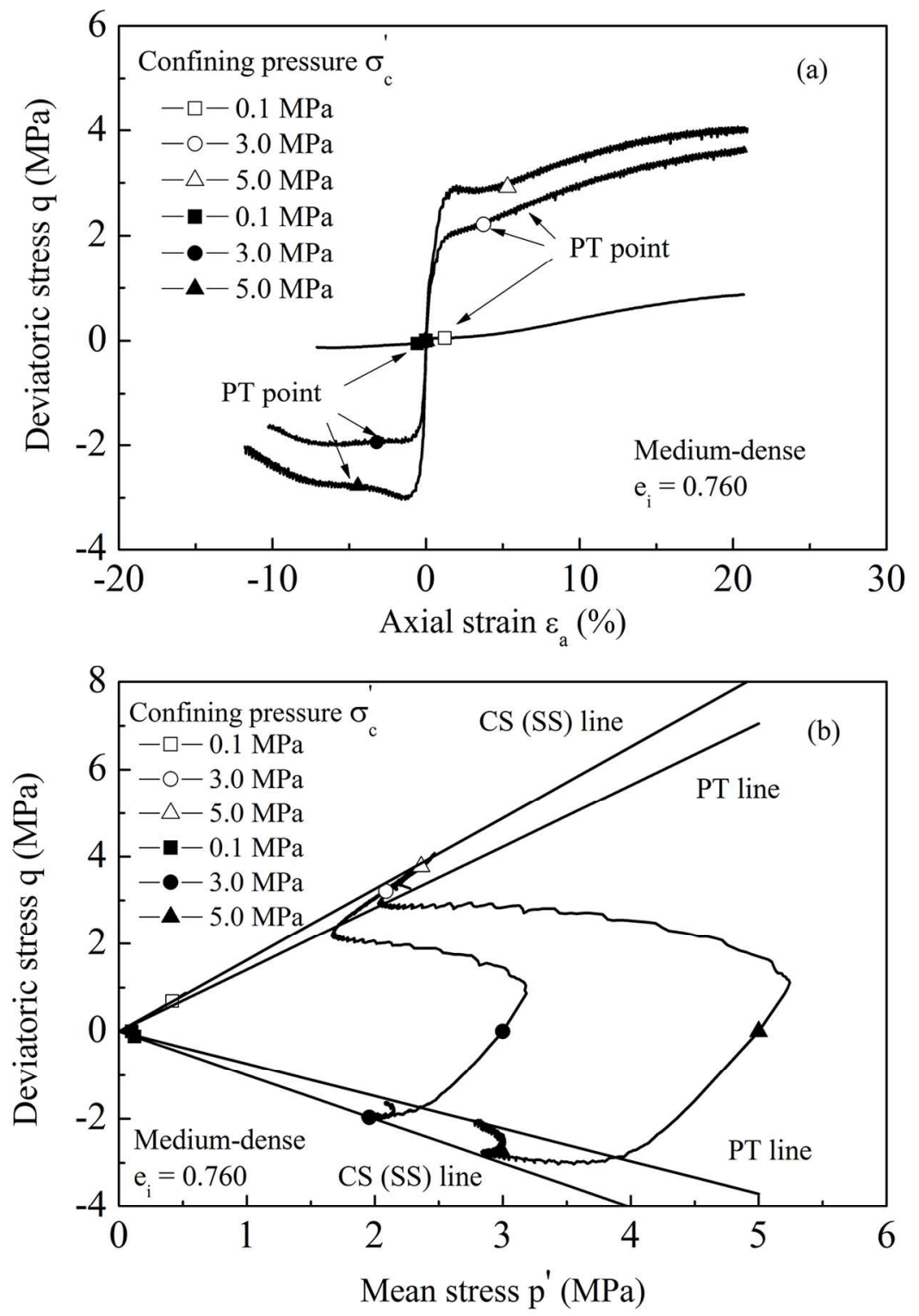

Fig. 6 Undrained monotonic shear behaviour of medium-dense Aio sand with initial void ratio 0.760 at variable confining pressures (a) Stress-strain behaviour (b) Effective stress path

$119 \times 167 \mathrm{~mm}$ (300 x 300 DPI) 

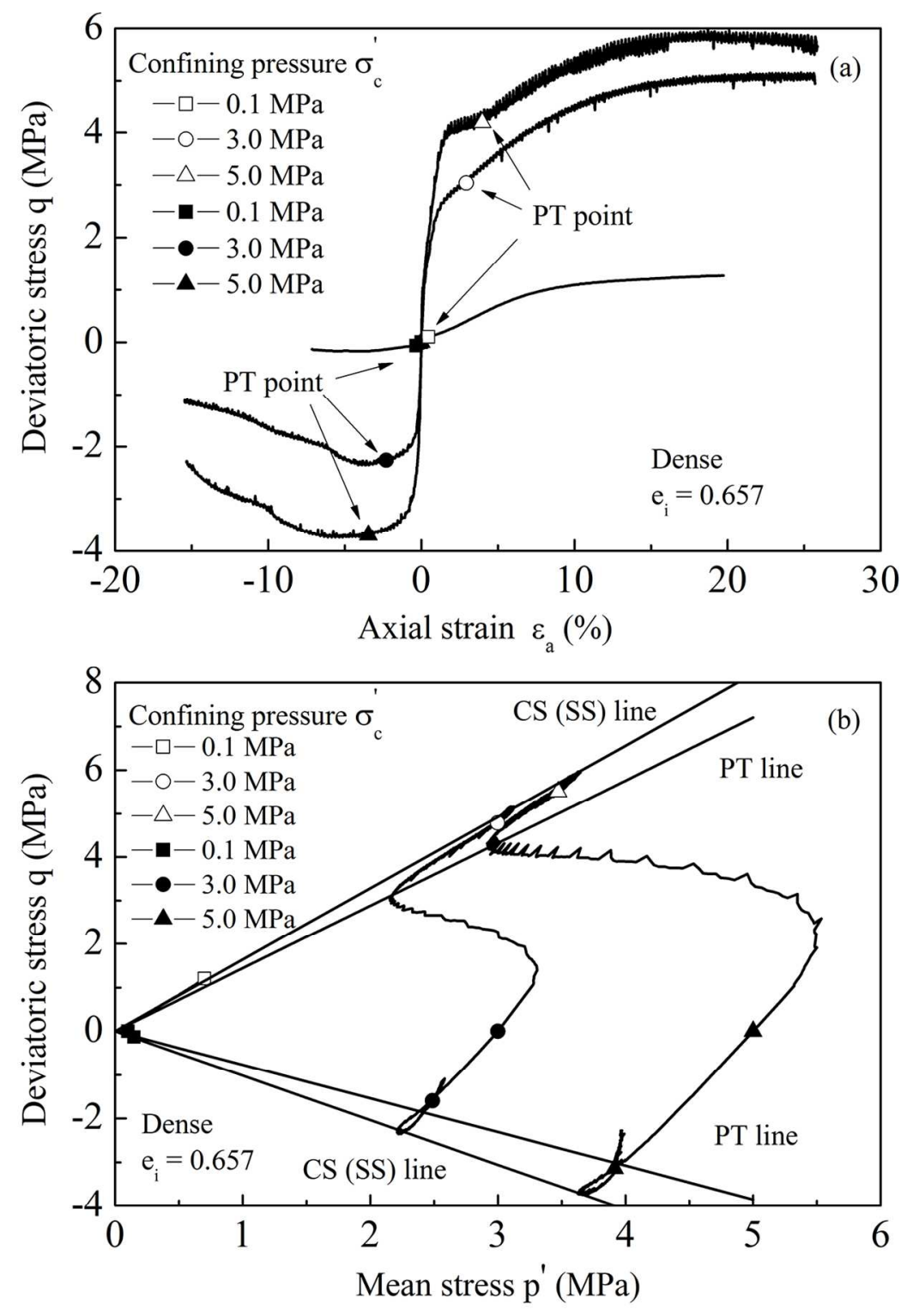

Fig. 7 Undrained monotonic shear behaviour of dense Aio sand with initial void ratio 0.657 at variable confining pressures (a) Stress-strain behaviour (b) Effective stress path (Hyodo et al. (2002))

$119 \times 167 \mathrm{~mm}(300 \times 300 \mathrm{DPI})$ 


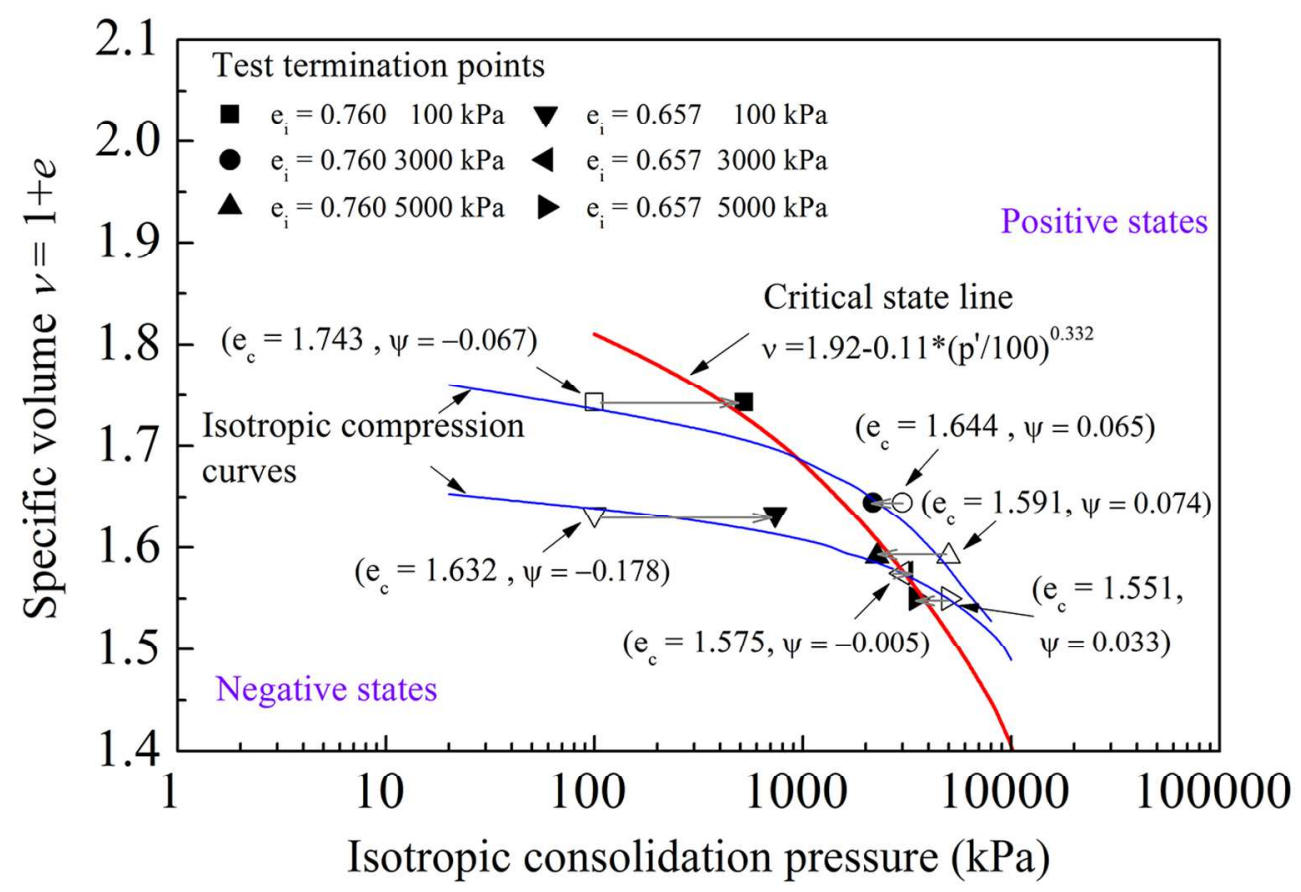

Fig. 8 State paths and end of test states on the specific volume and stress plane $119 \times 83 \mathrm{~mm}(300 \times 300 \mathrm{DPI})$ 


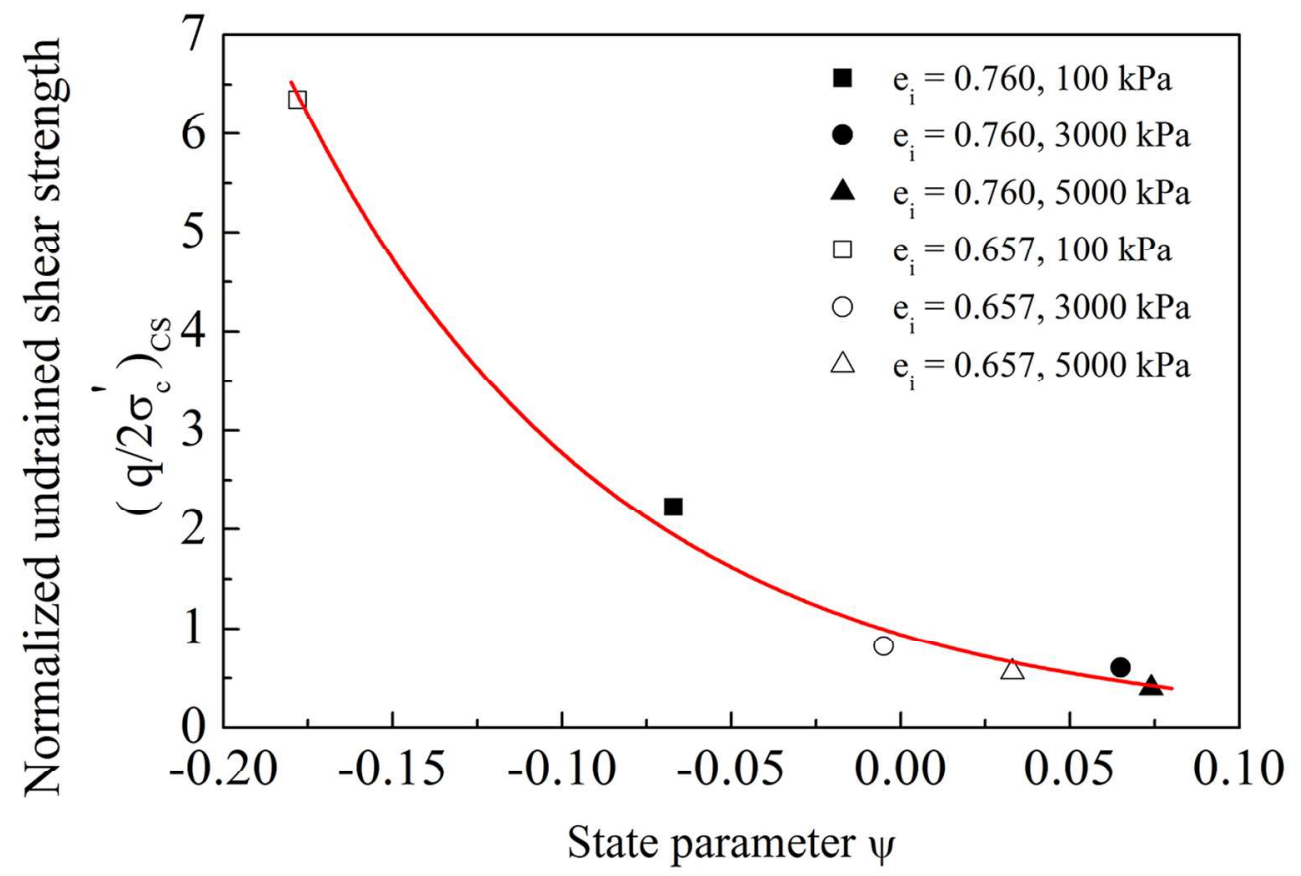

Fig. 9 Normalized undrained shear strength at critical state and state parameter $119 \times 83 \mathrm{~mm}(300 \times 300 \mathrm{DPI})$ 

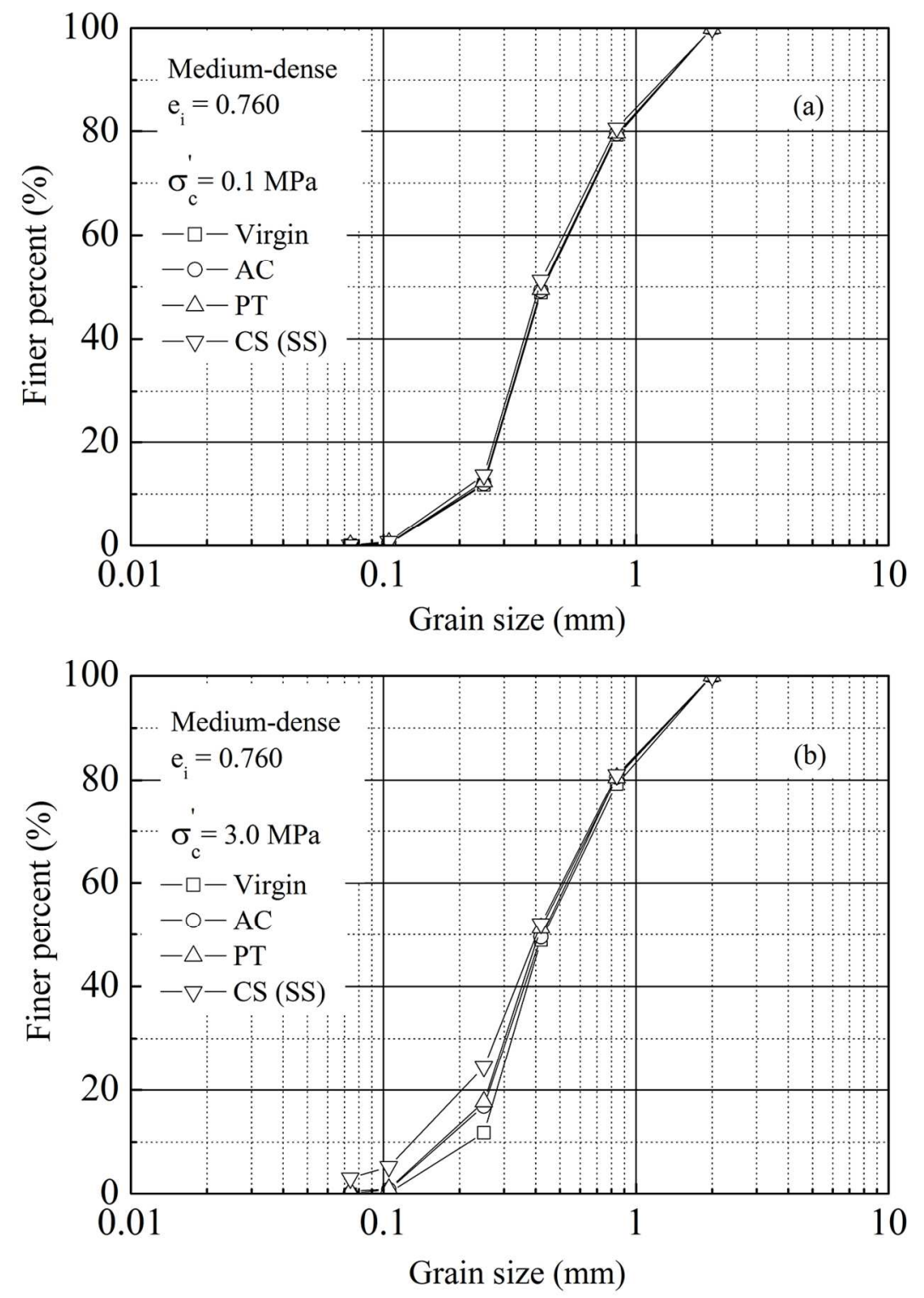

Fig. 10 Grain size distribution curves of medium-dense Aio sand before testing, after consolidation, at phase transformation point and critical state point (a) At confining pressure of $0.1 \mathrm{MPa}$ (b) At confining pressure of $3.0 \mathrm{MPa}$

$119 \times 167 \mathrm{~mm}(300 \times 300$ DPI $)$ 


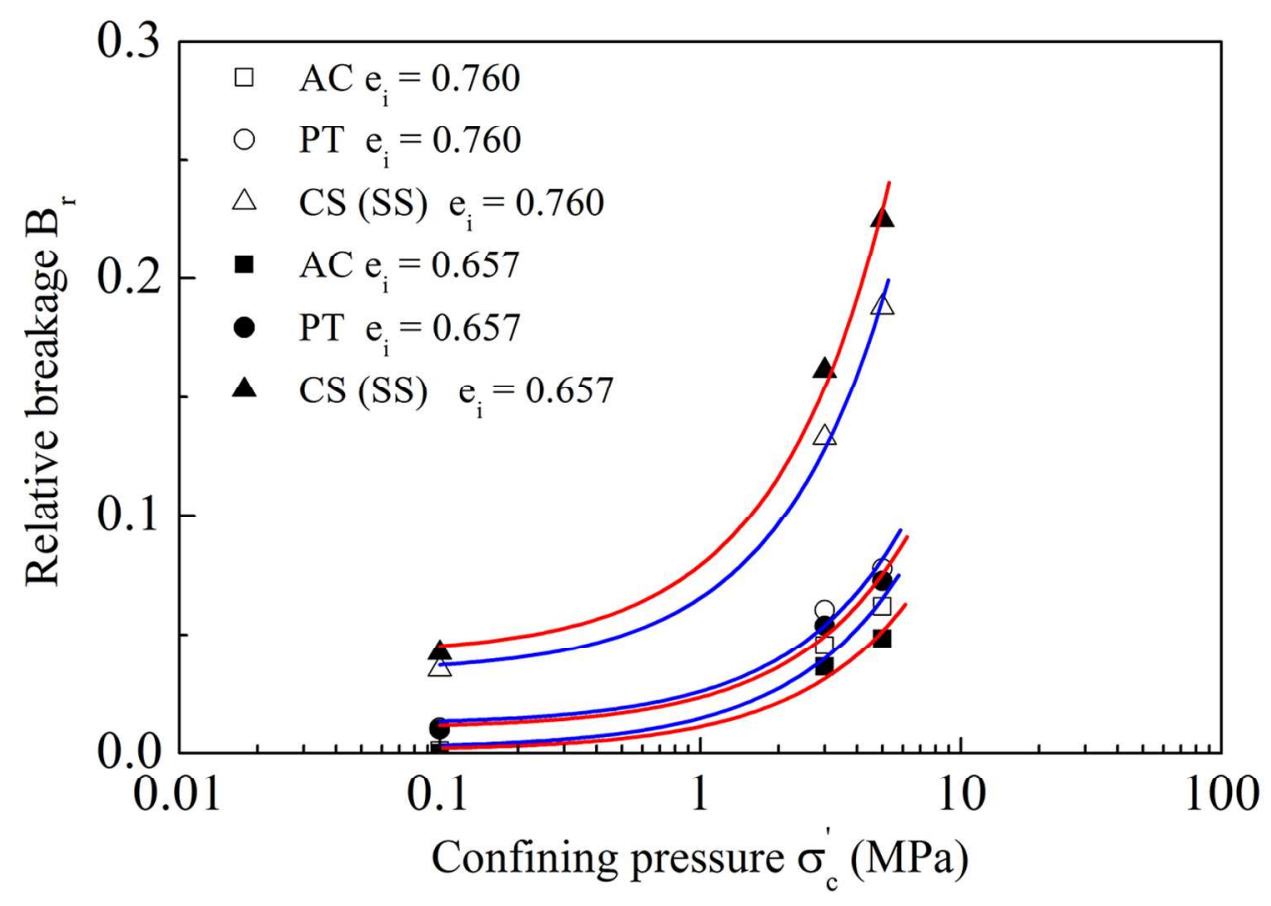

Fig. 11 Relative breakage after consolidation, phase transformation point and critical state point at variable confining pressures in undrained monotonic triaxial test

$119 \times 83 \mathrm{~mm}(300 \times 300 \mathrm{DPI})$ 


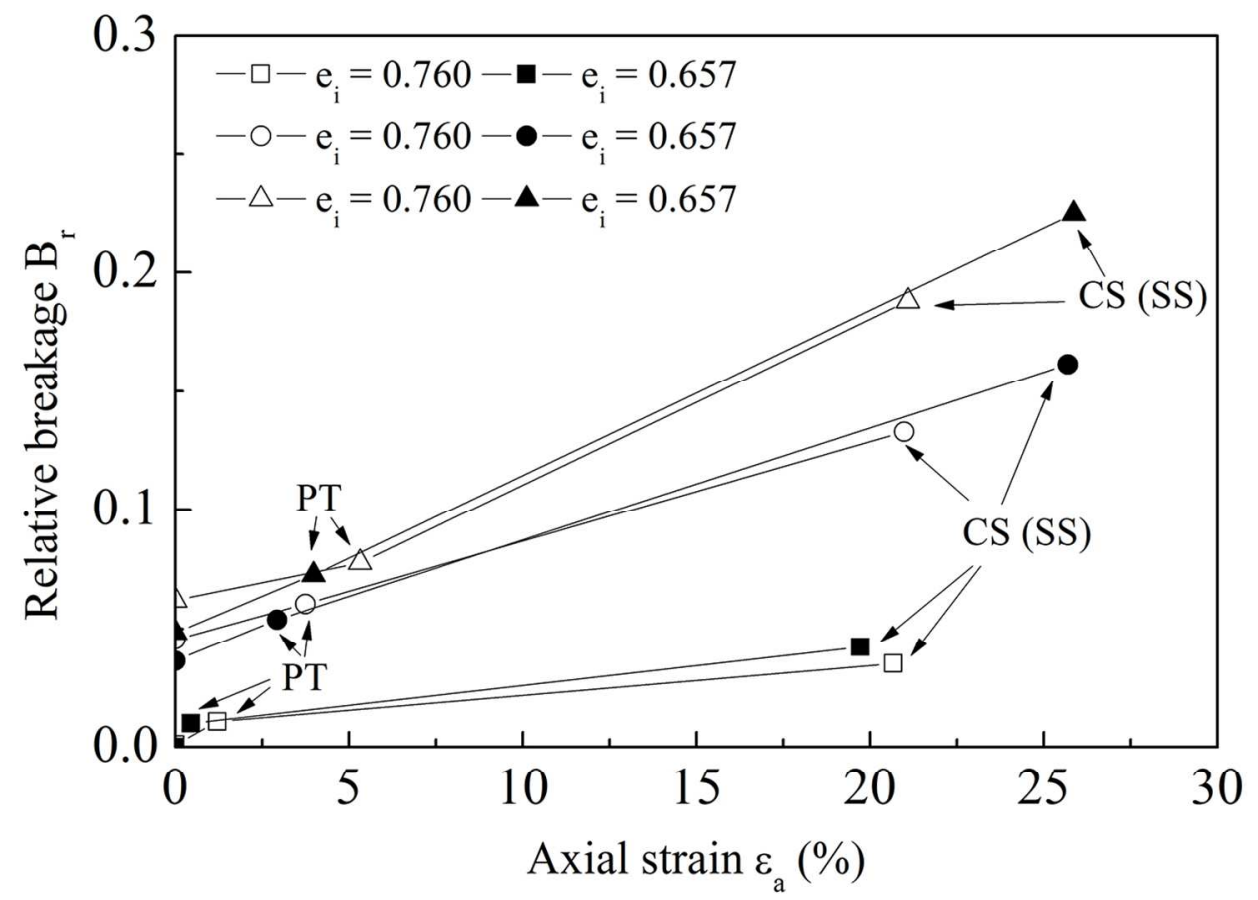

Fig. 12 The relative breakage plotted against the axial strain at variable confining pressures $119 \times 83 \mathrm{~mm}(300 \times 300 \mathrm{DPI})$ 


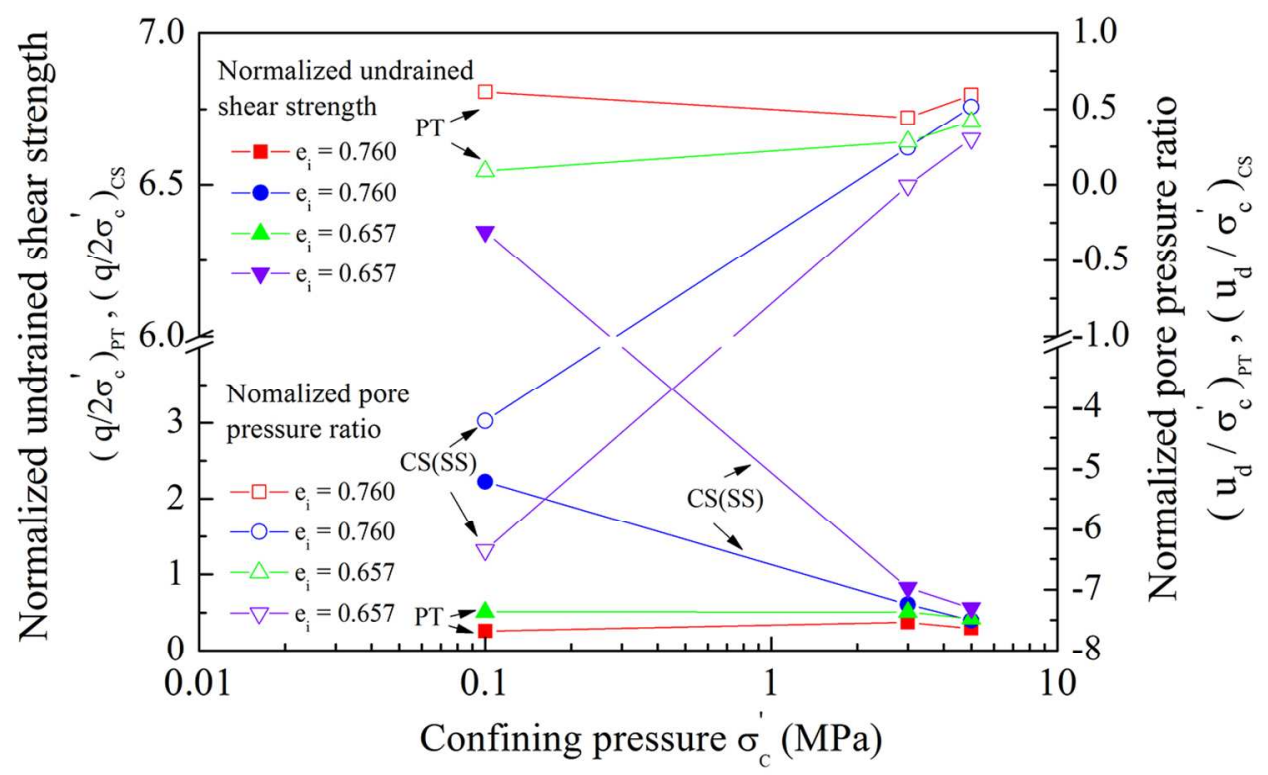

Fig. 13 Normalized undrained shear strength and normalized pore pressure ratio plotted against confining pressure

$119 \times 73 \mathrm{~mm}(300 \times 300 \mathrm{DPI})$ 

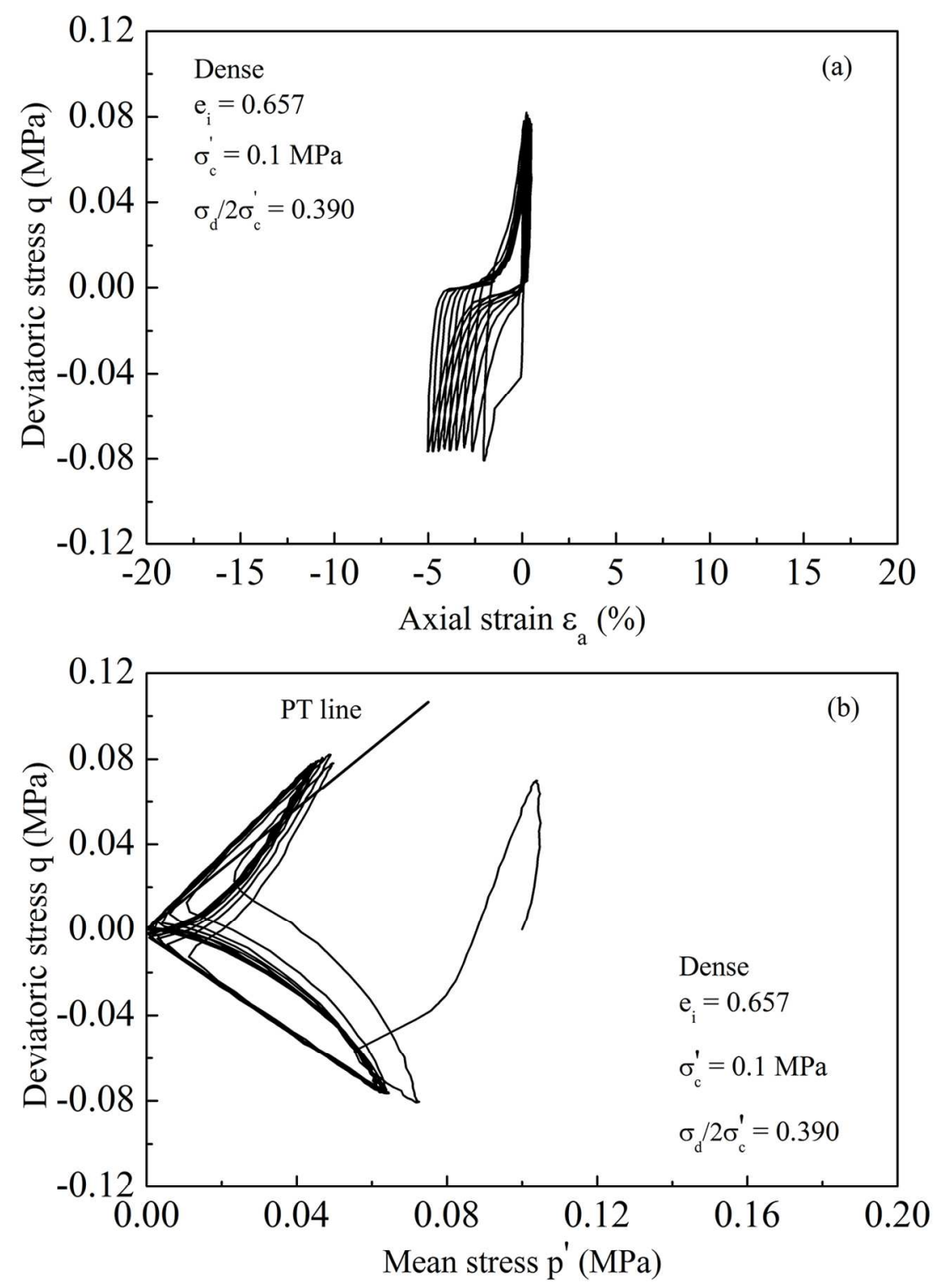

Fig. 14 Undrained cyclic response of dense Aio sand at confining pressure of $0.1 \mathrm{MPa}$ (a) Stress-strain curve (b) Effective cyclic stress path (Hyodo et al. (2002))

$119 \times 167 \mathrm{~mm}(300 \times 300 \mathrm{DPI})$ 

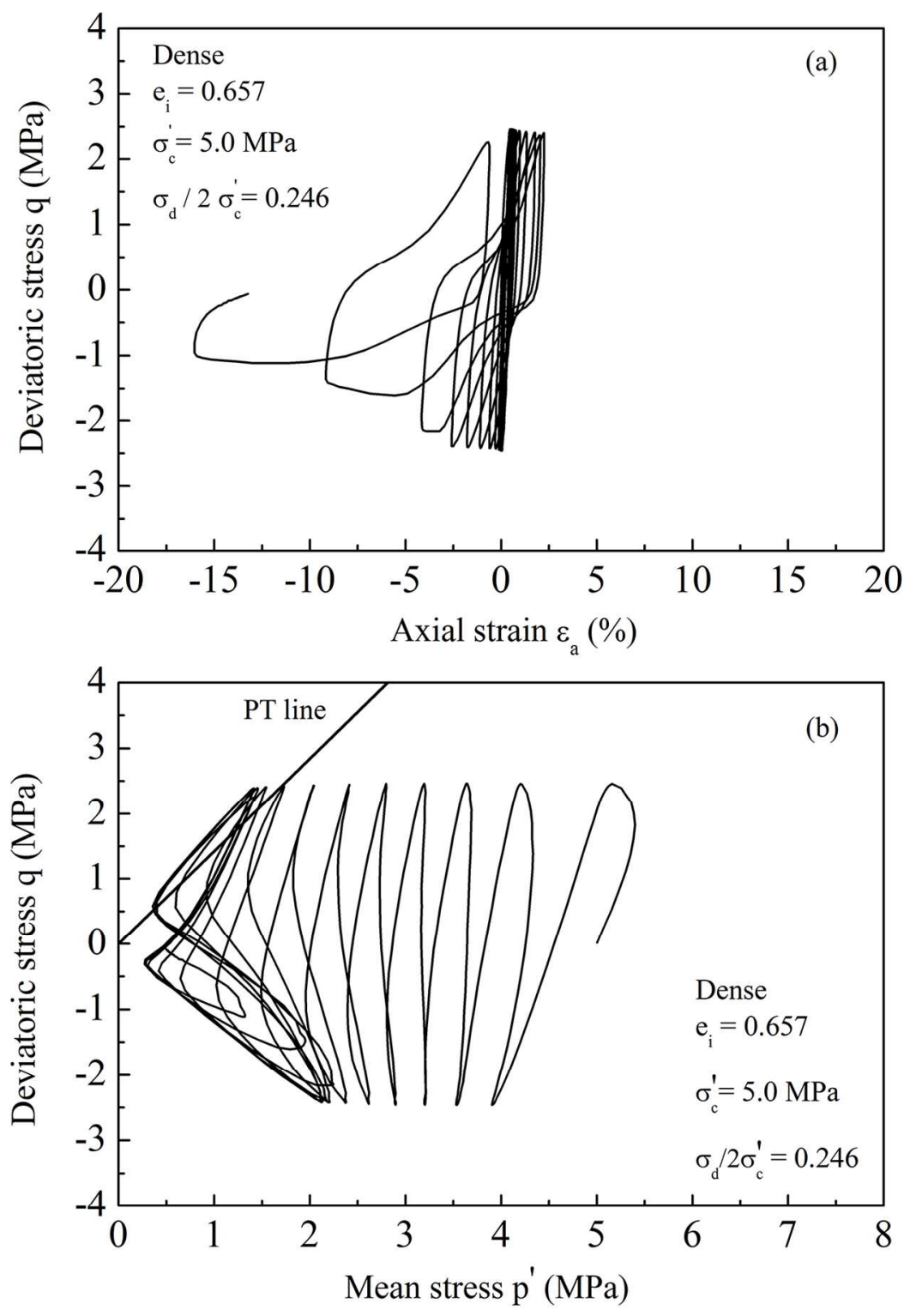

Fig. 15 Undrained cyclic response of dense Aio sand at confining pressure of 5.0 MPa (a) Stress-strain curve (b) Effective cyclic stress path

$119 \times 167 \mathrm{~mm}(300 \times 300 \mathrm{DPI})$ 


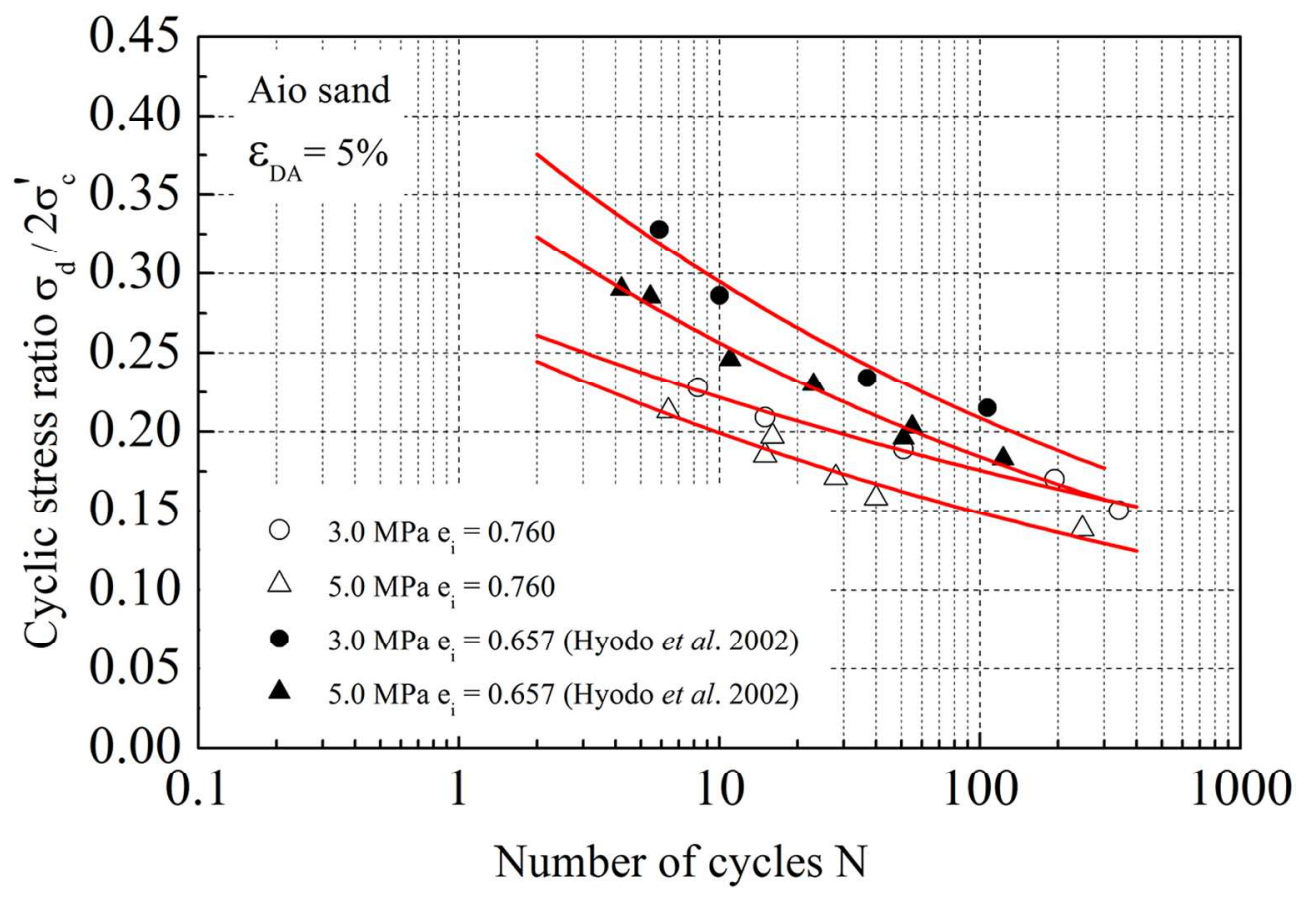

Fig. 16 Liquefaction resistance strength of Aio sand with two initial void ratios of 0.760 and 0.657 $119 \times 83 \mathrm{~mm}(300 \times 300 \mathrm{DPI})$ 


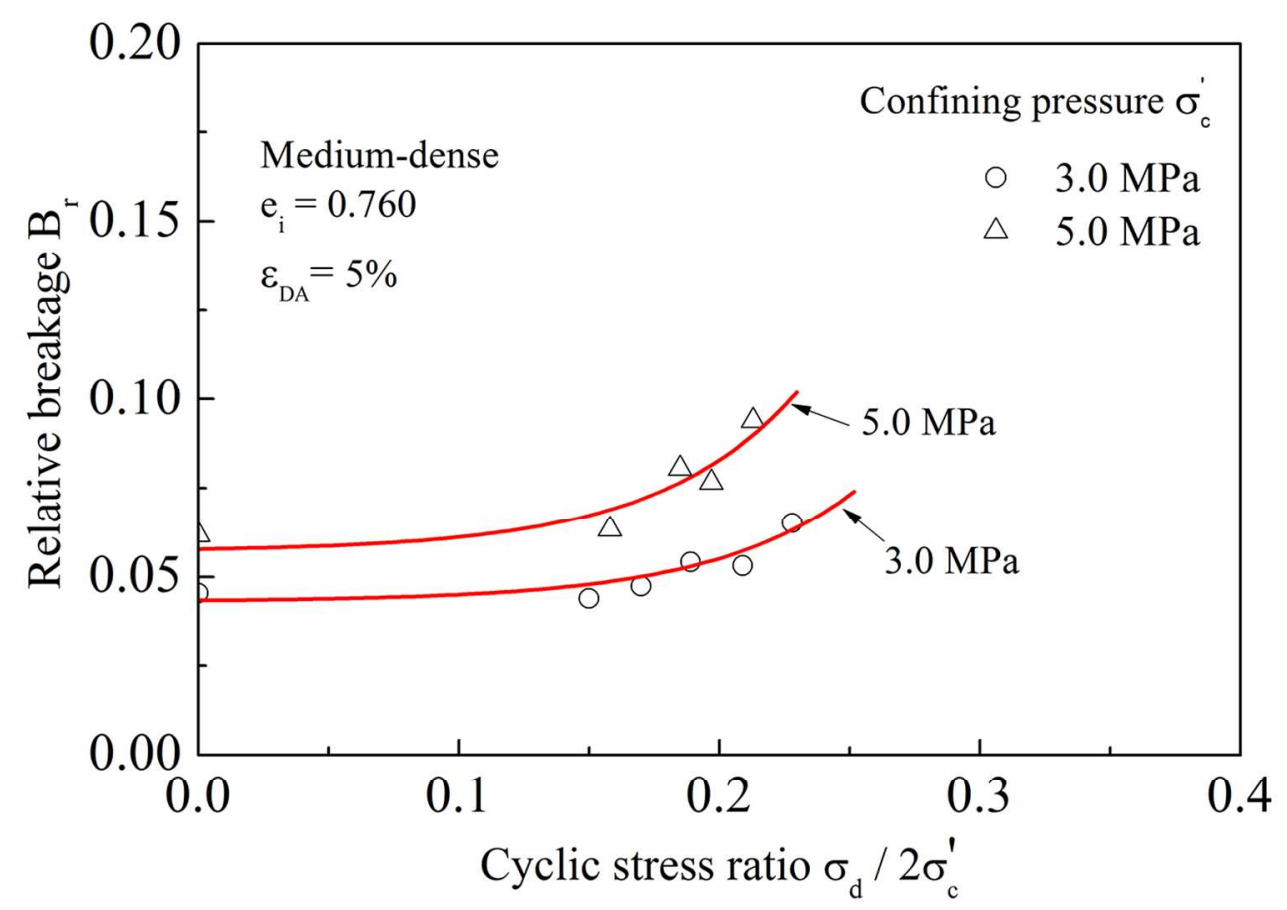

Fig. 17 Relative breakage plotted against the cyclic stress ratio of medium-dense Aio sand $119 \times 83 \mathrm{~mm}(300 \times 300 \mathrm{DPI})$ 


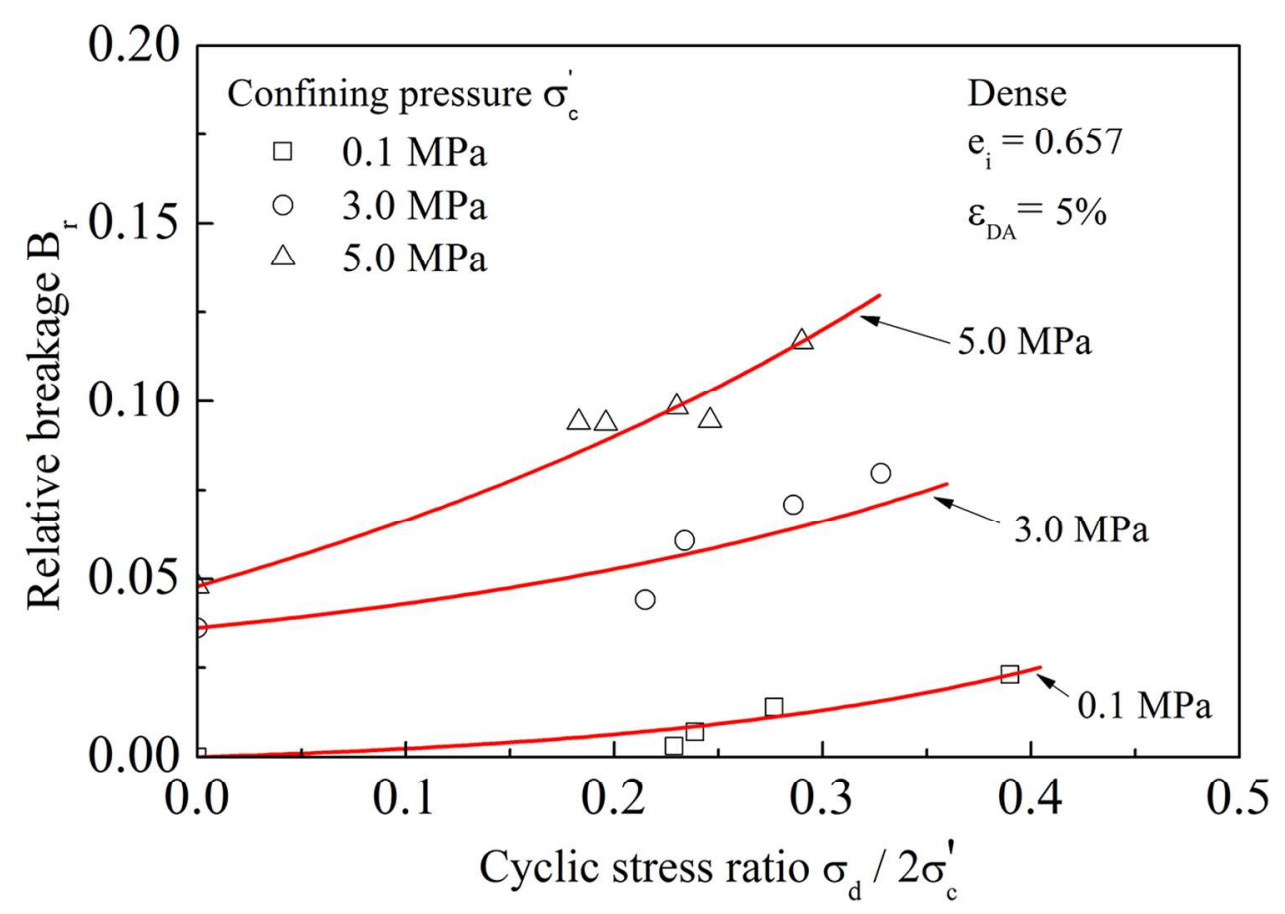

Fig. 18 Relative breakage plotted against the cyclic stress ratio of dense Aio sand $119 \times 83 \mathrm{~mm}(300 \times 300 \mathrm{DPI})$ 


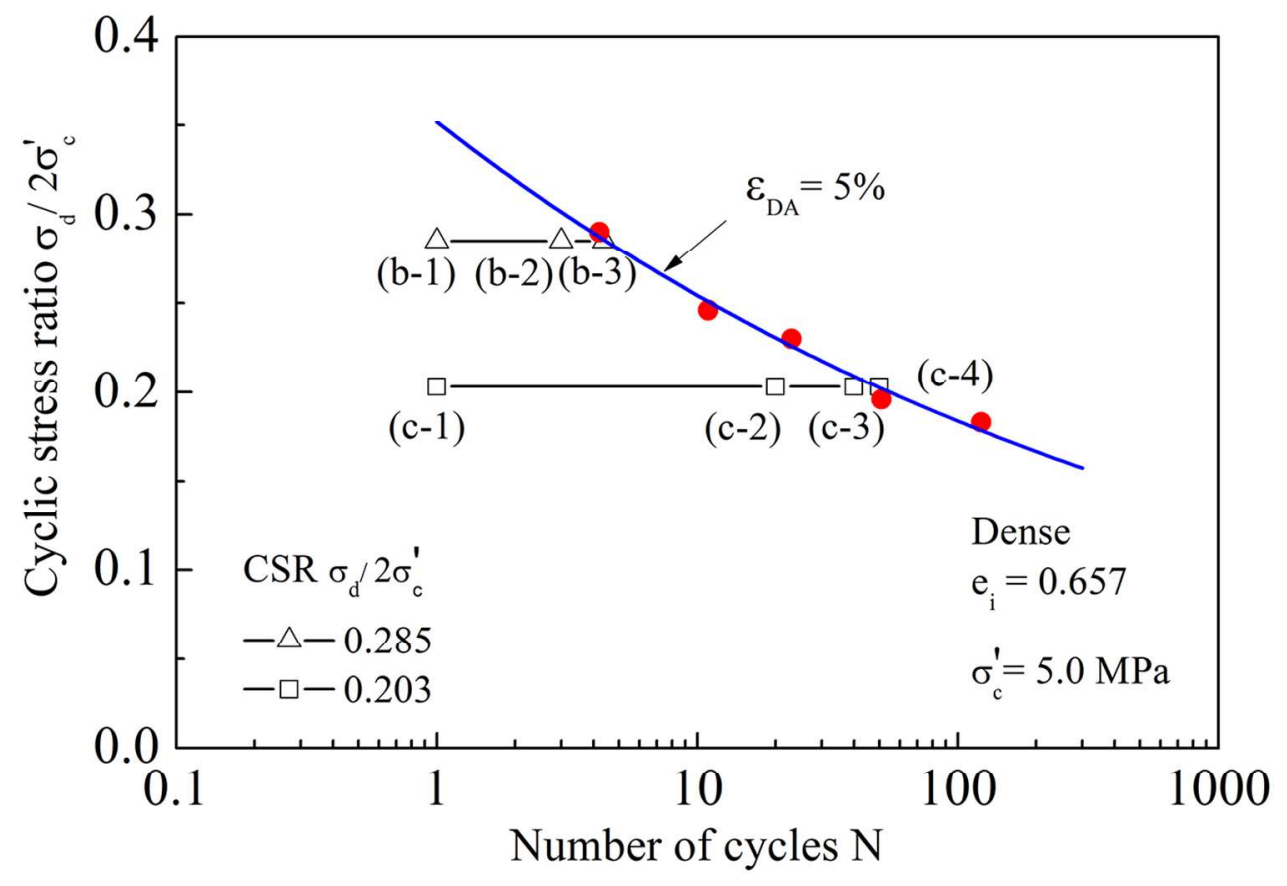

Fig. 19 Stress path at different cyclic stress ratios of dense Aio sand in undrained cyclic test (Hyodo et al. (2002))

$119 \times 83 \mathrm{~mm}(300 \times 300$ DPI $)$ 


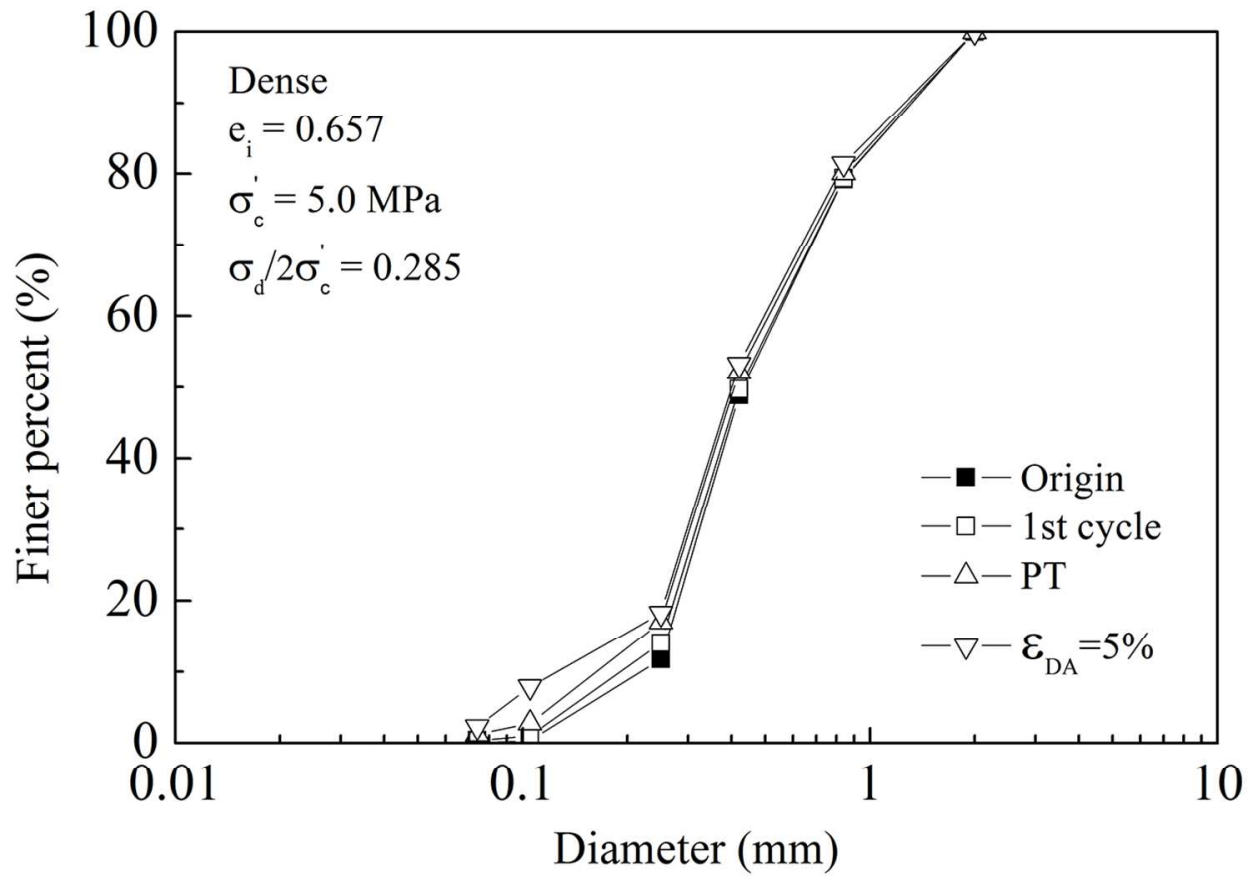

Fig. 20 GSD curves of dense Aio sand at different stages in undrained cyclic test at confining pressure of 5.0 $\mathrm{MPa}$

$119 \times 83 \mathrm{~mm}(300 \times 300$ DPI $)$ 


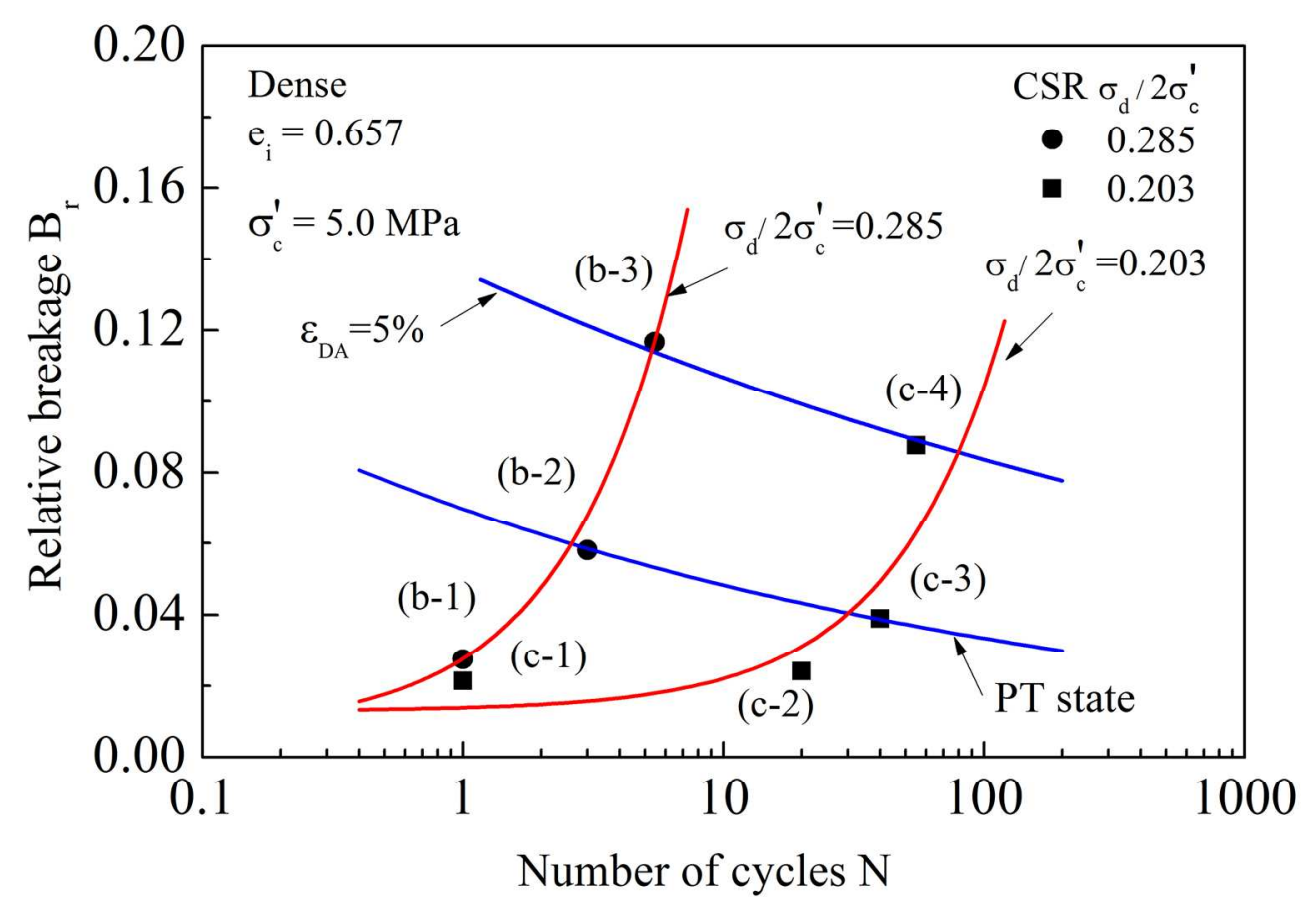

Fig. 21 The evolution of particle crushing at different cyclic stress ratios of dense Aio sand at confining pressure of 5.0 MPa in undrained cyclic test

$171 \times 119 \mathrm{~mm}(300 \times 300 \mathrm{DPI})$ 


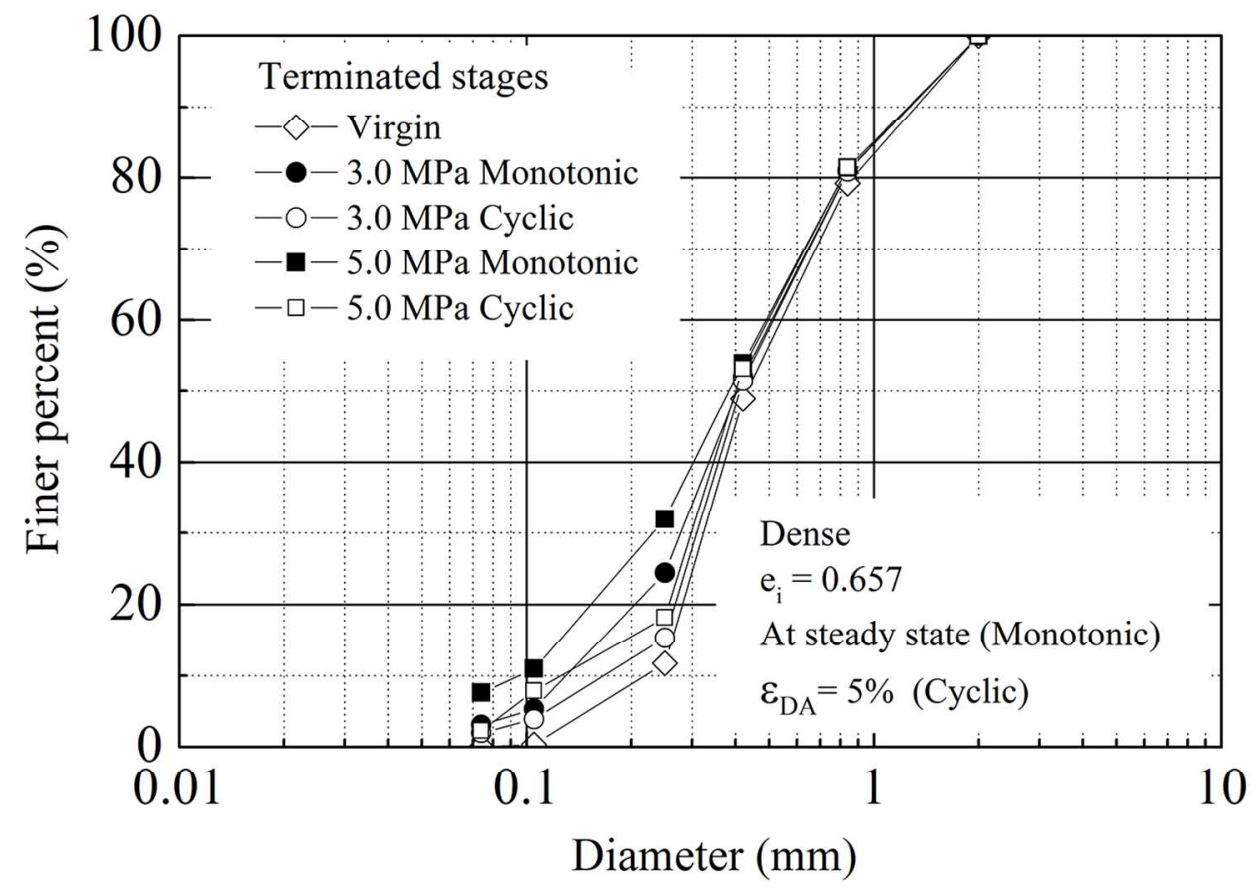

Fig. 22 Effect of loading mode on the particle crushing in undrained conditions $119 \times 83 \mathrm{~mm}(300 \times 300$ DPI) 


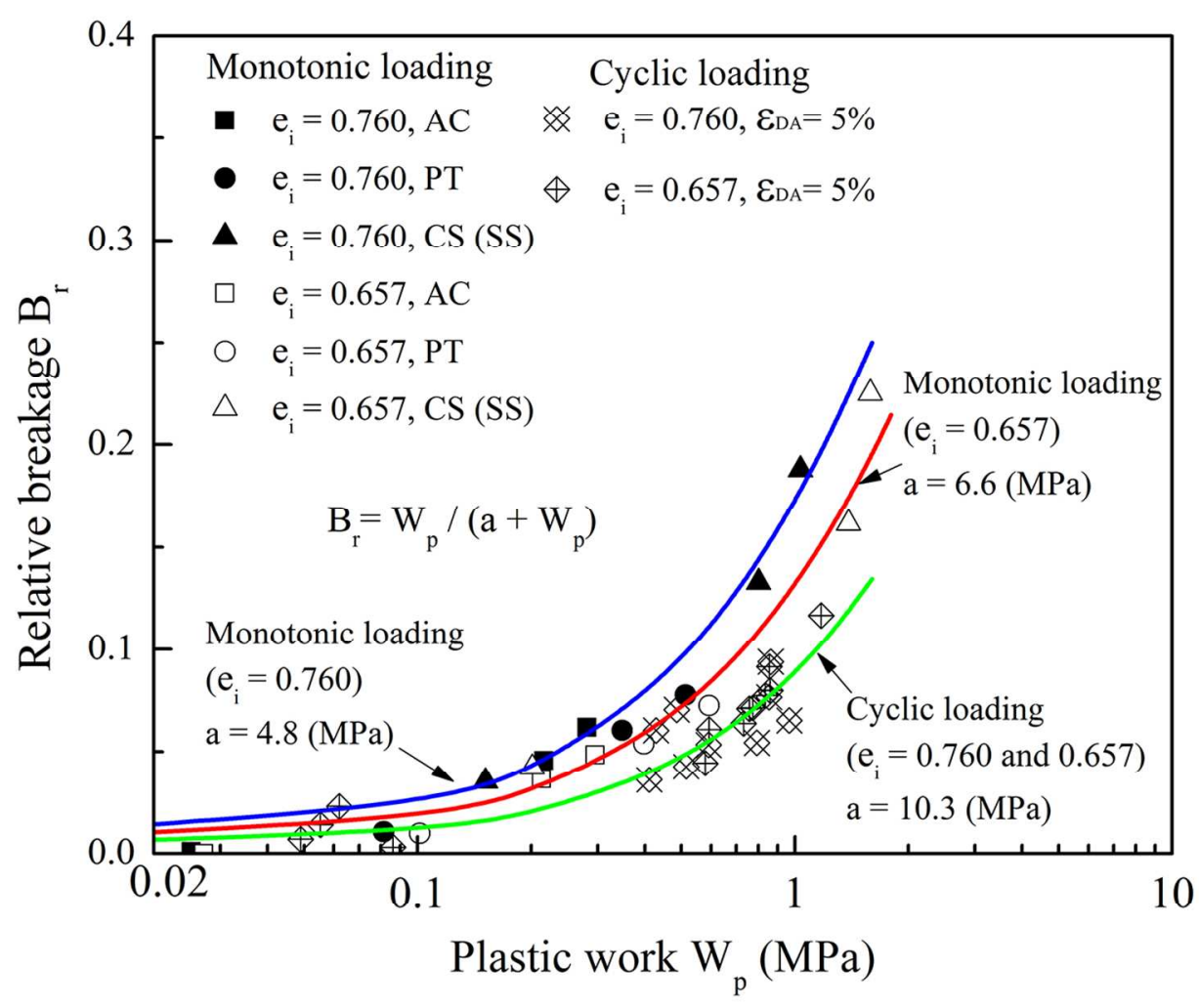

Fig. 23 Correlation between relative breakage and plastic work under isotropic consolidation, undrained monotonic and cyclic tests

$119 \times 98 \mathrm{~mm}(300 \times 300 \mathrm{DPI})$ 